Document downloaded from:

http://hdl.handle.net/10251/165597

This paper must be cited as:

Alcaide-Marzal, J.; Diego-Mas, JA.; Acosta-Zazueta, G. (2020). A 3D shape generative method for aesthetic product design. Design Studies. 66:144-176.

https://doi.org/10.1016/j.destud.2019.11.003

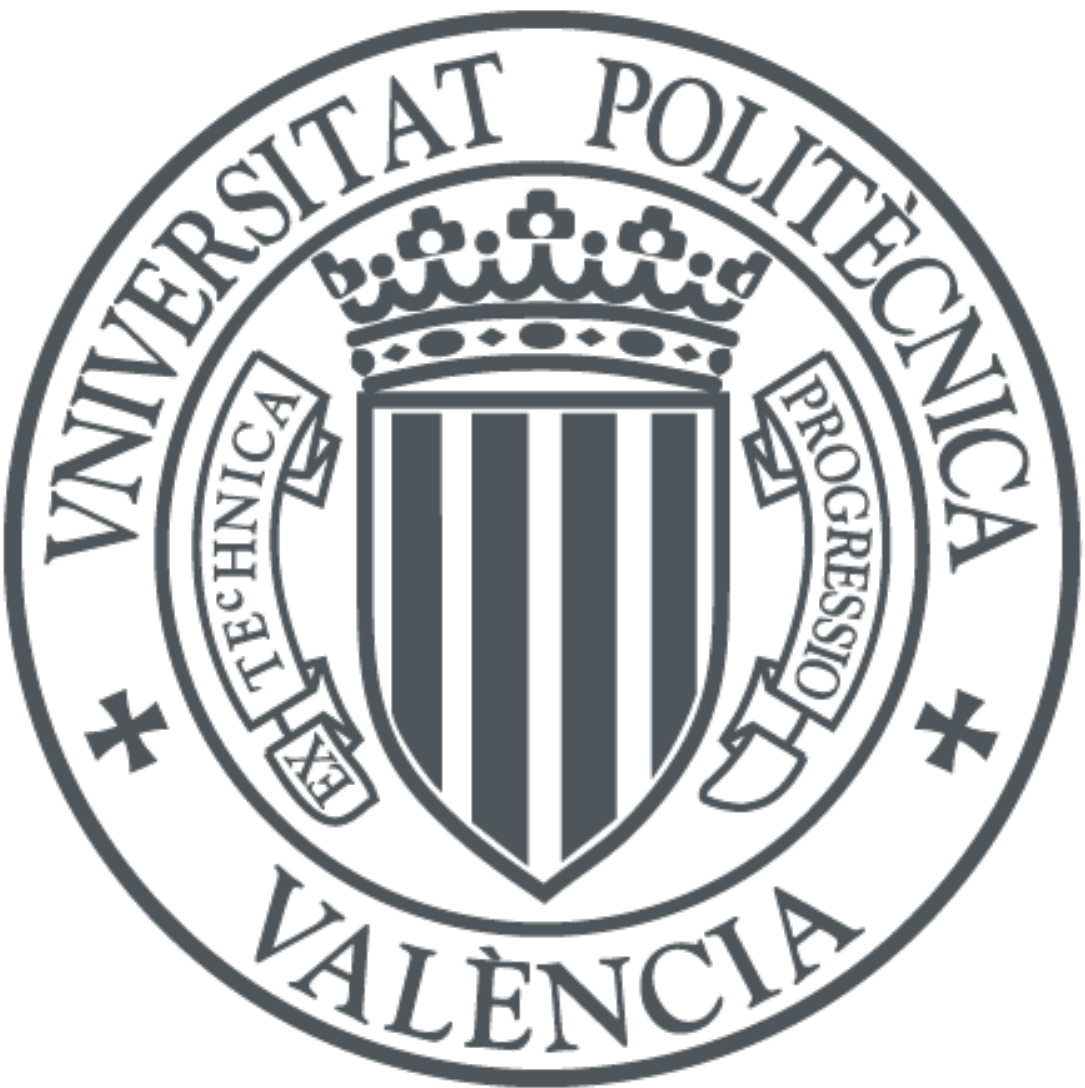

The final publication is available at

https://doi.org/10.1016/j.destud.2019.11.003

Copyright Elsevier

Additional Information 


\title{
A 3D shape generative method for aesthetic product design.
}

\begin{abstract}
.
In this work, we present a generative method for the exploration of product shapes in the conceptual design stage. The method is based on three concepts: the use of a parametric modeller to build shapes, the notion of grammars to capture product visual appearances and the assimilation of sketch transformation rules into the system to produce variations. We utilize a combination of morph boxes and $2 \mathrm{D}$ and $3 \mathrm{D}$ generic shapes to build the product. This procedure allows many different configurations with a minimal set of shapes, and permits the adaptation of models from a product to another. The performance of the method is demonstrated through several examples extracted from the literature.
\end{abstract}

Keywords: Aesthetics; generative modelling; computer aided conceptual design; shape exploration

\section{Introduction.}

The visual appearance is very often a fundamental attribute of a product. During the conceptual stage, designers explore the solutions space and try to conceive suitable appealing concepts that subsequently elaborate in the following stages. Many authors have studied the processes that lead to successful product concepts, as well as the obstacles to creativity that hamper the designer tasks at this stage (Boden, 2004; Cross, 1997, 2008; Dorst \& Cross, 2001). A relevant research field related to formal design focuses on the relationship between sketching (as product shape or solution depiction) and creativity (Do, Gross, Neiman, \& Zimring, 2000; Goel, 1995; Goldschmidt, 1991; Obrenovic, 2009; Schon \& Wiggins, 1992; Suwa \& Tversky, 1997; van Sommers, 1984).

One of the most studied creativity blockers is fixation (Jansson \& Smith, 1991), a phenomenon by which the designer tends to stick to a limited space of familiar solutions instead of opening to new and unexplored paths.(Crilly, 2015; Crilly \& Cardoso, 2017; Vasconcelos \& Crilly, 2016). This is such an important blocker that might deserve an own research field (Crilly \& Cardoso, 2017).

The scientific community has conducted an intensive research on methods and techniques aiming to foster creativity (Wang \& Nickerson, 2017). Some works focus specifically in the field of computer assisted creativity (Bernal, Haymaker, \& Eastman, 2015; Gabriel, Monticolo, Camargo, \& Bourgault, 2016; Gero, 2000; X. Liu, Li, Pan, \& Li, 2011; Lubart, 2005), and many researchers have analysed the influence of the use of computers in creative performance of designers. (Chang, Chien, Lin, Yiching, \& Hsieh, 2016; Company, Contero, Varley, Aleixos, \& Naya, 2009; Robertson \& Radcliffe, 2009).

Nevertheless, the use of computers in this stage is a disputed question, particularly related to CAD software. Some of the reasons that advise against it are the ambiguous and uncertain nature of the conceptual design stage, the lack of special stimulus that processes like hand sketching provide or the need for efficiently producing many concepts (Krish, 2011).

One of the proposed approaches to computer aided concept design is generative design (Bernal et al., 2015). It is a relatively new discipline in industrial design. It is more widely 
spread in architecture design (Krish, 2011; Singh \& Gu, 2011), where the algorithmic nature of the generated geometry fits perfectly into the modern building aesthetics. However, in the past few years, a specific approach of generative design related to structural shape optimization is growing stronger in the engineering field, and new proposals are arising in broader scopes.

Generative design may constitute a different way of breaking creative blockings by letting the computer produce alternatives. The designer can explore a wider range of possible product designs in a comparatively much lower time, so new aesthetic options may emerge. (Bernal et al., 2015) hold that this mechanism nearly reproduces the "coevolving dialog between problem and solution that characterizes expert designers" (Dorst \& Cross, 2001), but they stress the lack of reformulation tools. (Hyun \& Lee, 2018) point out the need for flexible computational approaches focused on form exploration and capable of producing a high number of concepts.

This paper proposes the use of generative shape modelling to explore product aesthetic alternatives. We combine an interactive parametric modelling system with the notion of "product vocabulary" from shape grammars and sketch transformation rules in order to create a concept generator for stylistic product design.

\section{Using computers for creative product styling.}

\subsection{From a representation tool to an idea generator.}

The role of computers in the conceptual stage of the design process has been a matter of discussion since the very existence of CAD. (Bernal et al., 2015; Dekker, 1992; Lubart, 2005; Tovey, 1997; van Dijk, 1995; Van Elsas \& Vergeest, 1998; Vuletic et al., 2018). The special nature of the tasks involved in this stage, which has been for a long time incompatible with the way CAD works, constitutes one of the main obstacles to an efficient use of computers in the ideation phase.

From the point of view of concept shape generation, the scientific community has driven its efforts towards two main areas: analysing and improving the designer-computer interaction experience and studying the combination of human and machine capabilities.

The first research corpus studies the suitability of CAD systems to provide a proper tool for conceptual design and tries to find better conditions and propose changes in order to improve their performance. Due to the abundance of studies about the relationship between sketching and creativity, researches try to conceive and analyse computer tools that emulate or favour the traditional sketch workflow.

Therefore, most of these works consider the implementation of sketch gestures in the modelling process (Company et al., 2009; Cook \& Agah, 2009; Olsen, Samavati, Sousa, \& Jorge, 2009; Samavati, Sousa, \& Jorge, 2008; van Dijk \& Mayer, 1997). Other works focus on the analysis of software interfaces (Hewett, 2005; Machado, Gomes, \& Walter, 2009; Selker, 2005) or the use of new paradigms in modelling and representation, most of them also sketch based (Alcaide-Marzal, Diego-Más, Asensio-Cuesta, \& PiquerasFiszman, 2013; Bae, Balakrishnan, \& Singh, 2008; Igarashi, Matsuoka, \& Tanaka, 1999; Rahimian \& Ibrahim, 2011). In the 90s, some works use the term Computer Aided Conceptual Design to refer to this kind of software (van Dijk, 1995; Van Elsas \& Vergeest, 1998)

The second research corpus investigates how to use the power of computers in order to help designers to perform creative tasks more efficiently, or even to make the computers produce solutions. This is the computational creativity approach (Gabriel et al., 2016) 
and may include any computer application capable of generating product shapes not directly built by the designer.

Algorithmic design procedures constitute the main research interest in this area. Different algorithm implementations have been proposed and studied, being shape grammars and evolutionary models the most frequent. According to (Bernal et al., 2015), the computer aided conceptual design research focus has evolved from the first approach (computer as an optimized shape representation tool) to the second one (computer as an intelligent tool able to manipulate concepts and generate ideas). The authors, however, raise several objections to this second approach, related to the limitations of CAD to handle no hierarchical data and the difficulties to implement the designers' expertise and instinct in computer systems. These obstacles would prevent the computer to act as a designer.

We agree. Nevertheless, according to (Stones \& Cassidy, 2010), designing digitally is more related to computers allowing designers to explore solutions beyond what they can draw or imagine than to designers using computers to more efficiently represent shapes. This is what Mitchell called "digitally mediated design" (Granadeiro, Duarte, Correia, \& Leal, 2013). The computer does not substitute the designer, but it is neither a mere representation tool. If used properly, its computational power may produce many suitable alternatives, allowing the exploration of new solution fields and overcoming fixation. We will discuss this computational (generative) approach in the next section.

\subsection{Generative product design.}

Generative design practices are still in an early stage in product design disciplines. Krish describes its evolution stressing the lack of a theoretical framework to work with (Krish, 2011). Generative design involves the evaluation of a product state and the subsequent application of suitable rules. The concept seems having found more attraction in architecture (Chase, 2005; Rodrigues, Amaral, Gaspar, \& Gomes, 2015; Shea, Aish, \& Gourtovaia, 2005; Singh \& Gu, 2011), although progressively, new contributions are appearing in other different disciplines such as graphic layouts (Cleveland, 2010), electronic consumer products (Lin \& Lee, 2013), jewellery (Kielarova, Pradujphongphet, \& Bohez, 2013) or interface design (Troiano \& Birtolo, 2014).

Shape Grammars are among the most utilized generative methods. They have been widely used since Stiny and Gips introduced them in their seminal work (Stiny \& Gips, 1972). The work of (Agarwal \& Cagan, 1996) is one of the first using shape grammars for product design. (Hsiao \& Chen, 1997) combine shape grammars with a semantic approach to define significant shape structures for an office chair. Later, a work by (Hsiao \& Wang, 1998) used a similar approach to produce car designs.

An interesting contribution of the shape grammar concept is the formal research of brand identity features. The work of (McCormack, Cagan, \& Vogel, 2004) presents a study in which shape grammars are used to capture Buick brand identity and generate alternative coherent designs. Similar studies can be found related to Harley motorcycles (Pugliese \& Cagan, 2002), shampoo bottles (X. Chen \& McKay, 2004), Coca Cola bottles (McKay, Ang, Chau, \& Pennington, 2006) or Porsche frontends (Aqeel, 2015).

The idea of shape grammars is very appealing as a procedure to implement a tool to assist conceptual design by automatic generation of concepts. However, there is a need for methodologies to adequate them to specific design goals (Ruiz-Montiel et al., 2013). The complexity of object representations is also an obstacle to further development (Chase, 2002). Due to this, shape grammars are still in an early implementation stage into the product design toolset. 
(Krish, 2011) holds that the power of modern parametric CAD systems has overcome shape grammar approach. Parametric modelling allows the hierarchical representation of relationships in the product geometry, and the exploration of alternatives by modifying the parameters (Bernal et al., 2015). In (Granadeiro et al., 2013), the authors describe some works in which a transition from shape grammars to parametric design systems is performed. The conversion consists in translating the transformation rules of shape grammars into parametric equations and variables.

(Turrin, von Buelow, \& Stouffs, 2011) summarize several approaches to the use of parametric modelling as a Computer Aided Conceptual Design tool. They also propose a combination of parametric modelling and interactive genetic algorithms to control the concept generation.

Genetic algorithms are in fact among the most utilized methods for computational design exploration. (Renner \& Ekárt, 2003) offer a review of their application to computer-aided design. Since some early works such as (Bentley, 1998; Gero, 1996; Hybs \& Gero, 1992), many studies have tested the use of evolutionary algorithms in product design: Lamp holders (H. Liu, Tang, \& Frazer, 2004); shape optimization for mobile phones (J. Sun, Frazer, \& Mingxi, 2007); wine glasses profiles (Su \& Zhang, 2010). (Shieh, Li, \& Yang, 2018) use a combination of Kansei and evolutionary algorithms for vase designs. In (O'Neill et al., 2010) or (H. C. Lee, Herawan, \& Noraziah, 2012), genetic algorithms are combined with shape grammars.

Based on this genetic concept, (Krish, 2011) proposes a different approach to generative conceptual product design called Generative Design Method. Instead of a fitness function, it uses randomness controlled by means of the allowed variability of each gene. This proposal is simple and effective, and if set up properly, is able to generate many different solutions, depending on the product. Besides that, by avoiding the need for a fitness function constitutes a suitable system for subjective design problems, such as styling design. We will discuss this issue in the next section.

Although randomness allows introducing some chaos and unexpectedness into the process, it may also generate excessive divergence. Therefore, some works use different algorithms to ensure a homogeneous space exploration (Gunpinar \& Gunpinar, 2018; Khan \& Awan, 2018; Khan \& Gunpinar, 2018). (Dang et al., 2015) propose a probability density function combined with machine learning to avoid pure random concepts and focus generation in desired areas of the design space.

\subsection{The aesthetic factor.}

The consideration of subjective requirements, especially aesthetic ones, is an ongoing research problem when using shape grammars, genetic algorithms, parametric design or any other generative procedure as an aid to conceptual product design.

Shape grammars procedures use transformation rules that lead form one configuration to another, but possibilities of implementing aesthetic criteria into the process are still very limited. Works considering this factor are not very numerous. The aforementioned study of the Buick appearance is an example (McCormack et al., 2004).

On the other hand, genetic algorithms need an evaluable performance of the design in order to check the fitness of each individual in each generation. All of the aforementioned works either use a goal function to find an optimal solution or make use of some degree of interactivity. The use of human interaction is a widely utilized option to manage subjective issues in evolutionary systems $(\mathrm{H}$. Liu et al., 2004), such as the case of interactive genetic algorithms (Cluzel, Yannou, \& Dihlmann, 2012). 
There are also many examples of research work using interactive genetic algorithms in different product disciplines: fashion design (Gong, Hao, Zhou, \& Sun, 2007; Kim \& Cho, 2000; Mok et al., 2013), car styling (Cluzel et al., 2012; Dou, Zong, \& Nan, 2016; Kelly, Papalambros, \& Seifert, 2008), perfume bottles (Kielarova \& Sansri, 2017), garment design (Hu, Ding, Zhang, \& Yan, 2008). An interactive evolutionary system using shape grammars is proposed in ( $\mathrm{H}$. Lee \& Tang, 2006) to design cameras. (Hsiao, Chiu, \& Lu, 2010) use genetic algorithms and Kansei for styling of coffee machines.

The problem of including human interaction into the evolutionary system is that it slows down its performance, as humans cannot assess the alternatives as fast as the system is capable of generating them (Renner \& Ekárt, 2003), and they easily feel tired in this kind of tasks (Gong et al., 2007).

Therefore, some research focuses on the automation of the evaluation stage. (Lo, Ko, \& Hsiao, 2015) quantify product aesthetics by means of an evaluation equation extracted from aesthetic theories. They utilize it as a fitness function to make product solutions evolve towards more pleasant ones. (Gu, Xi Tang, \& Frazer, 2006) propose an IGA combined with neural networks. Similarly, (X. Sun, Gong, \& Zhang, 2012) propose an IGA with semi-supervised learning to design sunglass lenses. (Hsiao \& Tsai, 2005) use trained fuzzy neural networks as fitness function for a genetic algorithm to design electronic door locks. (Khan \& Awan, 2018) propose an approach that works either automatically or interactively, using Jaya algorithms to find optimal solutions. They use it to design several products such as wine glasses, ceiling lamps, motorbikes or loudspeakers.

\section{Proposed methodology.}

The analysis of the state of the art shows very promising research areas. Our approach, however, focuses mostly on the nature of the computer task. Although an effective and immediate connection between the computer-generated concepts and the detailed CAD models is very desirable, we think that currently, this goal heavily restricts the potential of a generative system to produce aesthetic solutions. Moreover, this kind of task is somehow unrelated to the typical paper and pencil sketching process, resulting in several of the disadvantages that human designers find when trying to work with traditional CAD systems in the conceptual design stage.

We look for a computer tool able to assist the designer to explore conceptual product volumetric shapes. At this stage, these shapes do not need to be completely correct or fulfil exact functional requirements; they just need to be intuitively adequate, as if they were pencil sketches. According to (Bernal et al., 2015) reinterpretation may also occur when using computers. Therefore, unexpected shapes produced by a generative system are potentially capable of suggesting new solution paths for the designer to follow. However, these authors also point out the lack of reformulation capabilities as a drawback of generative design. This may be true if we consider a static use of generative design. Nonetheless, if the generative system provides a high degree of interactivity to the designer, making possible to modify any parameter at any time, then reformulation is possible.

Hence, our proposal is based on an interactive generative system producing conceptual shapes. Following some authors (H. Liu et al., 2004; Stones \& Cassidy, 2010), it is not conceived as a product modeller, but as a style explorer. In fact, some authors recommend a separate computer system from detailed CAD modellers (van Dijk, 1995). Therefore, we have prioritized the variability of generated shapes over the topological precision and consequently over the CAD readiness. Namely, the system may generate geometrical combinations that may be incorrect but that give a proper visual idea of the suggested shape. For example, in general the system does not perform Boolean 
operations, to increase operational speed. Due to this, the solutions may present overlapping geometry. In fact, most of them do. They may also present disconnected geometry, although this is less frequent and easier to correct. The reason is that we do not expect the system to obtain CAD models ready to work on, but conceptual "3D sketch" models useful to inspire varied and hopefully unexpected and original shapes. As the purpose of these models is producing emergence, they may even be intuitively incorrect (Hsiao \& Chen, 1997).

This strong simplification serves another purpose: A high generality and variability of the system. Our aim is to define an open model, valid for almost any product and easy to adjust and modify to include new geometric features (Hoisl \& Shea, 2011). The use of combined general geometries instead of very product-specific ones helps in this goal.

(K. Chen \& Owen, 1998) present a generative system that separate products into spatial configurable volumes. A set of rules determine their relationships, incorporating stylistic as well as geometric information to the system. The model proposed in this work operates in a similar way. We divide the product shape into coherent volumes and represent them as a structure of morph boxes (product structure). The system is able to generate simple units of geometry, from 2D profiles to basic 3D bodies (product vocabulary). They are mapped into the boxes to build the representation of the concept. The boxes control the proportions and relationships between structure elements, while the profile and body generator control the geometric features at different levels. Every step is either controlled or randomized.

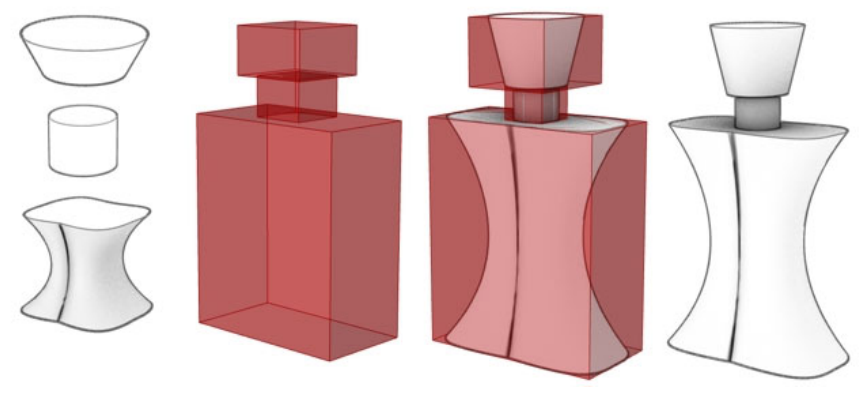

Figure 1. Mapping geometry onto morph box.

This strategy allows using the same geometric units in different parts of the product or in different products. There will be of course parts that will need specific shapes not suitable for other ones, but still in these cases, the possibility exists of trying just to explore shape combinations.

\subsection{Identifying an initial product grammar.}

The first step in the proposed method is to analyse a wide range of existing products in order to determine the initial grammar of the product. It is important to note that here we use the concept of "grammar" in a broad sense, referring to the basic shapes and geometric relationships that confer a product its visual identity.

The purpose of this stage is twofold. Firstly, we need to define the main volumes and features of the product, in order to determine its fundamental structure. Secondly, we pursue to identify predominant general shapes in this particular product, those that constitute its basic vocabulary. This information will allow us to feed the model with the essential elements that confer the product its geometric nature. Both goals are of course very straightforward in most of the existing products. However, a deep review of the product features and a subsequent implementation allows a more flexible product structure and a richer vocabulary, thus increasing the model ability to produce different 
concepts. A certain level of flexibility in the vocabulary is also convenient in order to favour the emergence of shapes with higher level of novelty.

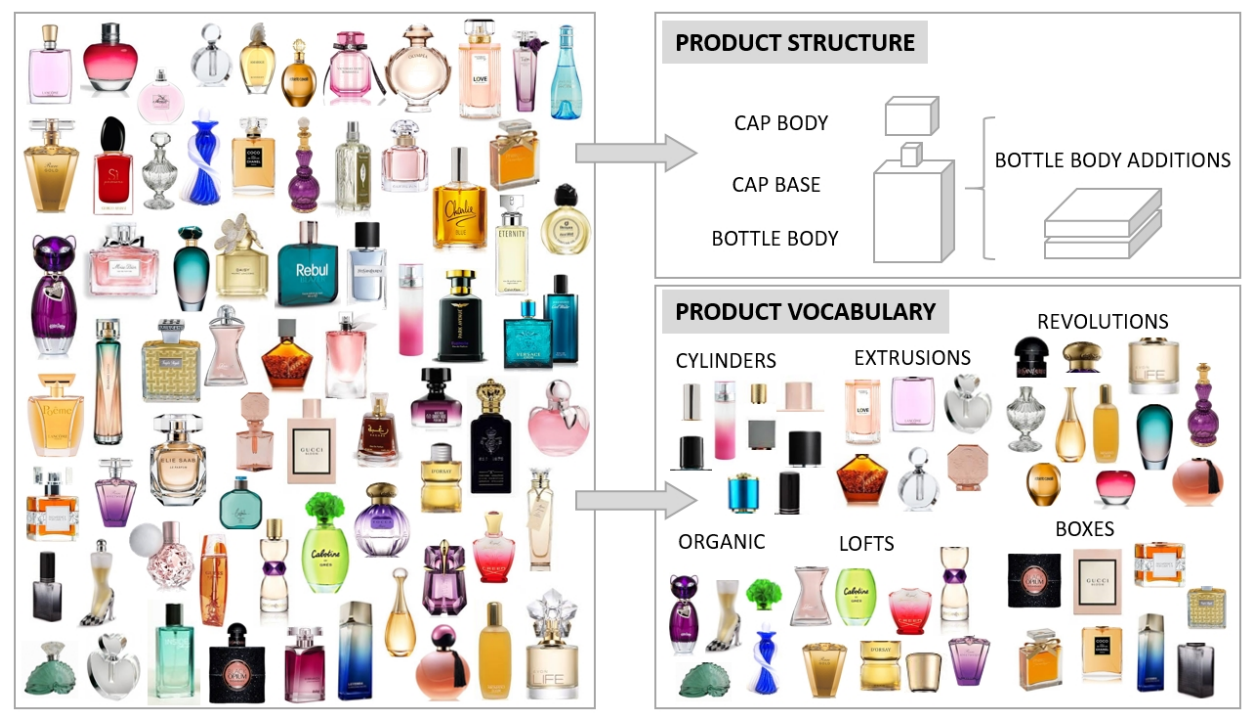

Figure 2. Product structure and vocabulary

The vocabulary is restricted if possible to combinations of primitive shapes and operations capable of generating most of the features detected in each volume. Our goal is to keep the basic units as general as possible as long as they are suitable to represent the product nature. The application of transformations or the addition of new volumes increase the model's complexity if needed.

\subsection{Setting transformation rules.}

Shape grammars use transformation rules to produce new shapes out of existing ones. These transformations may be translations, rotations, reflections, substitutions... Rules are applied by identifying an existing geometry, analysing the applicable rules and deciding which one to apply. Rules are usually specific to the product under study.

The proposed approach intend to keep the model as general as possible. We utilize the transformations described in (Prats, Lim, Jowers, Garner, \& Chase, 2009), where the researchers identify several "general rules" that designers use to produce different solution sketches. They recommend considering these rules when conceiving a computer aided design system. Some other works have already used this set of rules (Alcaide-Marzal et al., 2013; Kielarova, Pradujphongphet, \& Bohez, 2015). In this work, we have implemented them to replicate, in the system environment, the mechanisms used by designers to generate creative solutions. In fact, as the proposed system allows the participation of the designer in any moment, it very closely approximates the interactive workflow described in that paper. The designer builds an initial shape; the computer produces transformations over it; the designer uses them to refine the concept; the computer may produce new transformations over the refined ones, and so on. 


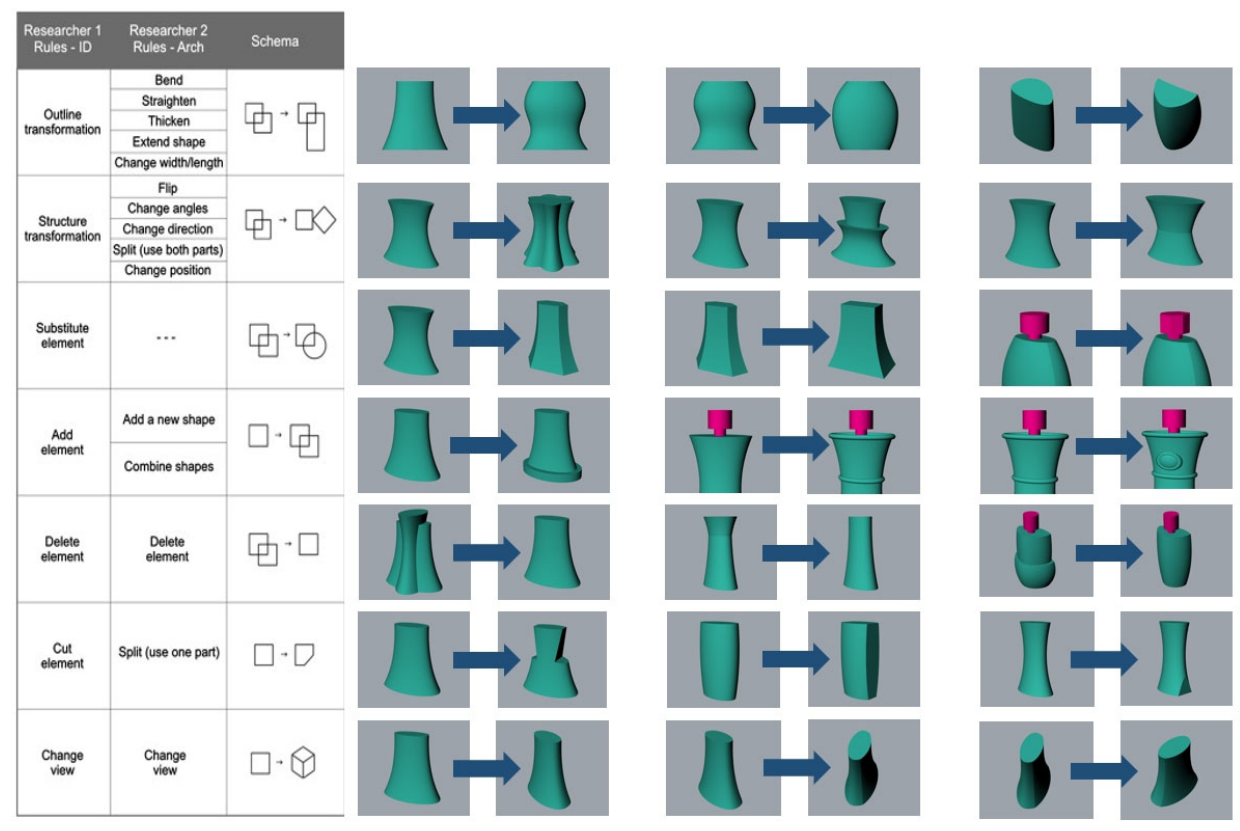

Table 1. Transformation rules

\subsection{Building the computer generative model.}

This stage is fundamental to achieve satisfactory results when producing solutions. (Krish, 2011) describes the need for a well-balanced model, capable of generating varied solutions but also feasible and geometrically coherent.

The computer generative model (CGM) has been built using Grasshopper 1.0.0006 for Rhinoceros V6. This software constitutes a very convenient way to implement generative design procedures, obtaining an immediate geometric result. Lately, its use in research involving algorithmic and generative design has increased notably.

The system consists of three major areas:

a) The first area is devoted to construction of basic parametric shapes, which constitute the basic product vocabulary. There are components that define 2D profiles such as basic shapes, polylines or random curves. They help to build 3D geometry (boxes, extrusions, revolutions, lofts). These shapes are adapted to fit the nature of a given product, depending on the analysis performed about its morphology. They also allows instilling a particular style, a personal trait or a desired set of features for the product, by implementing a defined geometry. This area produces mostly outline transformations, substitution and addition of geometry.

b) The second area reflects the product structure. Here, the designer may decide the general disposition of the product's main parts, by means of bounding boxes, which will receive the shapes generated in the first area. The designer can control the proportions of these boxes and their relative positions in order to generate variations. The system may as well randomly change these parameters, if the designer decides so. This area produces mainly structure transformations, substitutions, additions or deletions.

c) The third area allows applying transformations to the shapes rendered in the previous areas. These transformations may be translations, rotations, reflections, arrays, twists, scaling, trimming... These are structure transformation rules, addition and cutting. 

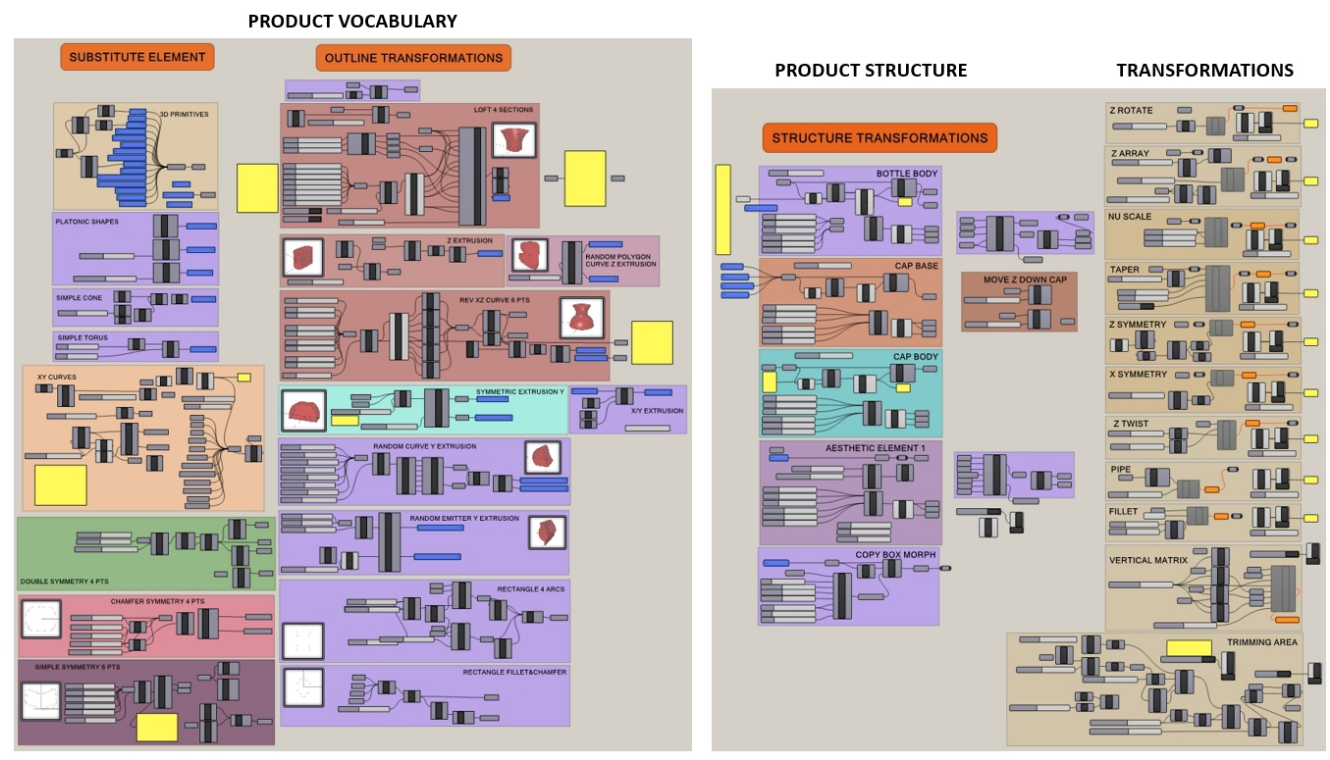

Figure 3. The CGM implemented in Grasshopper.

From a genetic perspective, the CGM represent the genotype of the product, the parameters being the genes. Different sets of values for each parameter produce different phenotypes. All of the parameters that control the geometry of the elements on each area may be either manually set or randomly generated. The designer may decide which parameters are fixed and which ones are to be randomized and to which degree. When the CGM generates a random concept, the designer may manually change any of the resulting features to finish or retouch it. It is also possible to produce a new random concept out of the existing one, keeping some features unchanged.

The CGM starts from an initial configuration, determined by the expression of different traits (geometries) and the value of each corresponding parameter (initial phenotype). The designer is able to define the probability of occurrence (PO) of each trait and the parameter variability (PV) of each feature, in order to explore the design space.

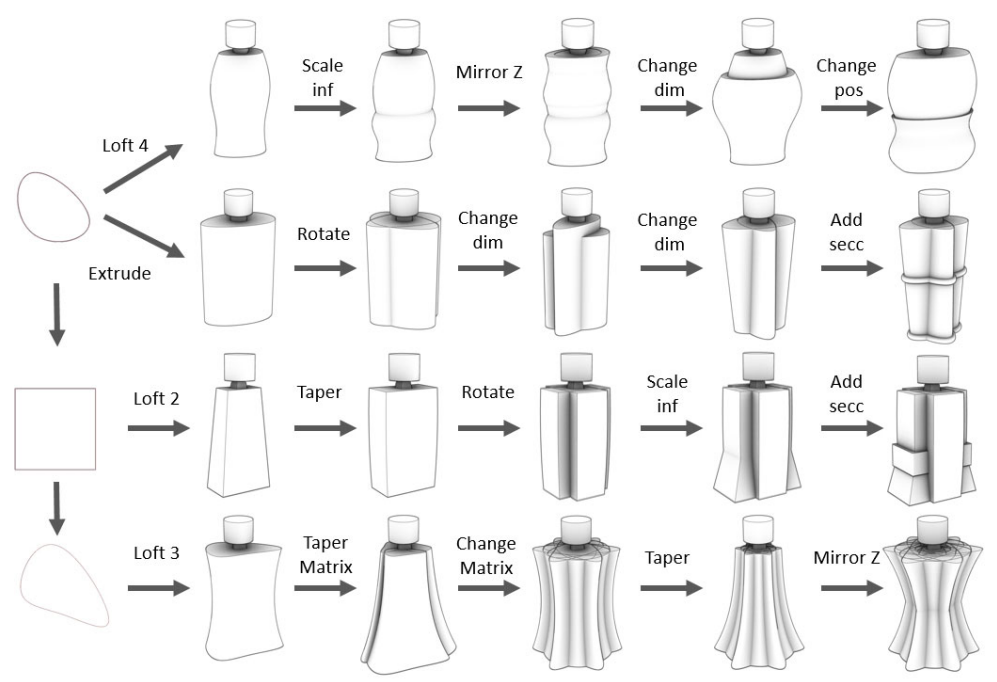

Figure 4. Application of rules over several 2D shapes 


\section{Exploratory case studies.}

Due to the difference of purposes, it is difficult to compare the performance of the proposed model against that of previous in the literature, which consider not only aesthetic shape generation but also functional requirements. Therefore, to validate the model we have developed versions of the CGM for many of the existing examples, analysing the behaviour of the model and its ability to represent effectively plausible and highly varied product geometries. We present this test in the following section. The first cases are described a little more in depth, to show the CGM possibilities.

\subsection{Perfume bottles.}

We have used for the first test perfume bottles, the same product as in the optimization study described in (Kielarova \& Sansri, 2017). In this work, objective design requirements are also considered. A similar product (shampoo bottles) is utilized in (X. Chen \& McKay, 2004), using a shape grammar approach to capture brand image, with no other restrictions.

(Kielarova \& Sansri, 2017) divide the bottle into three main sections (base, body and neck). We divide the genetic bottle model into three main volumes as well, but differently distributed (bottle body, cap base and cap body). Therefore, the initial structure consists of three main configurable volumes, plus two more additional volumes to add particular aesthetic details. This configuration may of course vary in many ways. It is possible, with little effort, to place more volumes where needed in order to enrich the concepts aesthetic. A sample of the grammar analysis is shown in previous section 2.1.

The bottle CGM grammar presents 16 configurable 2D shapes, 6 3D basic operations and 10 basic transformations plus some additional aesthetic options such as vertical arrays. Most of the 3D transformations are general, whereas many of the 2D shapes derive from the product analysis, allowing certain geometries to be present.

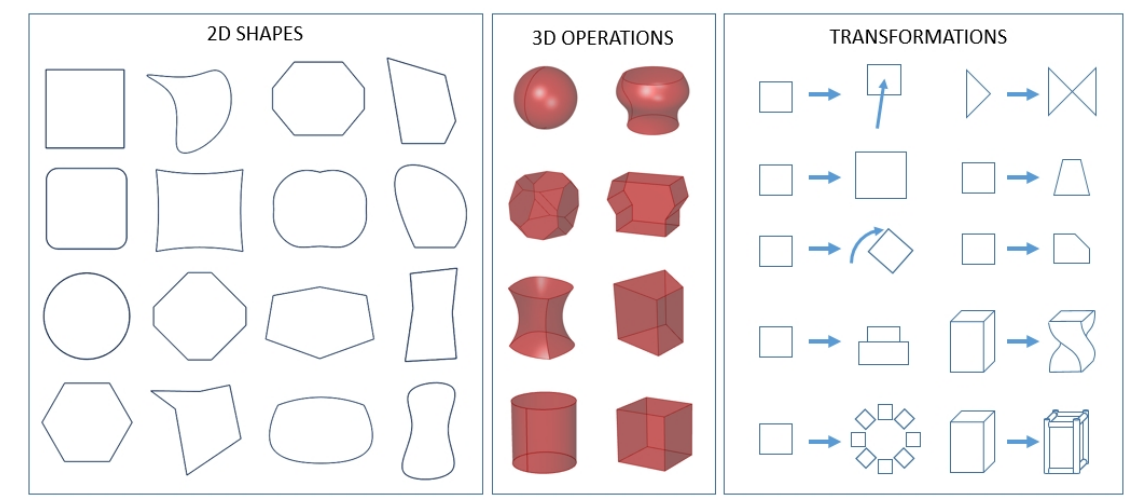

Figure 5. Perfume bottle basic grammar

The minimum configuration of the generative model (just one transformation of each kind) comprises 124 parameters. A random component controls each parameter, so as the designer can assign different randomization levels. 


\begin{tabular}{|c|c|c|c|}
\hline \multicolumn{4}{|c|}{ OUTLINE TRANSFORMATIONS } \\
\hline \multicolumn{2}{|c|}{ LOFT 4 SECT. } & \multicolumn{2}{|l|}{ CHAMFER SYMM 4 PTS } \\
\hline Plane heights & 3 & XY Coord. & 4 \\
\hline Section Curve & 4 & \multicolumn{2}{|l|}{ SIMPLE SYMM 6 PTS } \\
\hline Sections XY Dimensions & 8 & XY Coord. & 5 \\
\hline Loft Type & 1 & \multicolumn{2}{|c|}{ RECTANGLE FILLET \& CHAMFER } \\
\hline \# sections & 2 & Fillet/Chamfer radius & 1 \\
\hline Move section plane & 1 & \multicolumn{2}{|l|}{ RANDOM CURVE } \\
\hline \multicolumn{2}{|l|}{ REVOLUTION 6 PTS } & $X$ coord & 1 \\
\hline XZ Points Coord. & 9 & Vector Rotation & 3 \\
\hline Points On/Off & 3 & Vector Length & 3 \\
\hline \multicolumn{2}{|l|}{ DOUBLE SYMMETRY 4 PTS } & \multicolumn{2}{|c|}{ RANDOM EMITTER CURVE } \\
\hline XY Coord. & 2 & XY Coord. & 2 \\
\hline \multicolumn{2}{|l|}{ RECTANGLE 4 ARCS } & Polygon sides & 1 \\
\hline $\mathrm{XY}$ Arc radius & 2 & TOTAL & 57 \\
\hline Convexity & 2 & & \\
\hline
\end{tabular}

\begin{tabular}{|c|c|c|c|c|c|}
\hline \multirow{2}{*}{\multicolumn{2}{|c|}{$\begin{array}{l}\text { PRODUCT STRUCTURE } \\
\text { MAIN GEOMETRY (3 BOXES) }\end{array}$}} & \multicolumn{4}{|c|}{ 3D TRANSFORMATIONS } \\
\hline & & \multicolumn{2}{|c|}{ MOVE } & \multicolumn{2}{|l|}{ TAPER } \\
\hline XYZ Dimensions & 9 & XYZ Offset & 3 & Taper Degrees & 1 \\
\hline Inside shape & 3 & \begin{tabular}{|l|} 
On/Off \\
\end{tabular} & 1 & Taper Start/End & 2 \\
\hline Move Z shape & 2 & \multicolumn{2}{|l|}{ Z ROTATE } & Tapper Effect & 1 \\
\hline Move geometry & 3 & \begin{tabular}{|l} 
Rotation Degrees \\
\end{tabular} & 1 & On/Off & 1 \\
\hline \multicolumn{2}{|c|}{ AESTHETIC ELEMENTS (2) } & On/Off & 1 & X Z SYMMETRY & \\
\hline XYZ Dimensions & 6 & \multicolumn{2}{|l|}{ Z ARRAY } & Plane position & 2 \\
\hline Inside shape & 2 & \# elements & 1 & On/Off & 2 \\
\hline Plane Coord & 6 & XY Axis Offset & 2 & \multicolumn{2}{|l|}{ PIPE } \\
\hline Shape Indepth & 1 & On/Off & 1 & Pipe radius & 1 \\
\hline TOTAL & 32 & \multicolumn{2}{|l|}{ NU SCALE } & On/Off & 1 \\
\hline & & XYZ Scale & 3 & \multicolumn{2}{|l|}{ CUT } \\
\hline & & On/Off & 1 & Trim Plane & 4 \\
\hline & & \multicolumn{2}{|l|}{ Z TWIST } & Rect Cut Dim & 3 \\
\hline & & Twist Degrees & 1 & On/Off & 1 \\
\hline & & Twist start & 1 & TOTAL & 35 \\
\hline & & On/Off & 1 & TOTAL & 124 \\
\hline
\end{tabular}

Table 2. Perfume bottles parameters

Considering simply the shape combinations that we can achieve with this initial grammar, we get 56 main shape families (16 vertical extrusions, 16 horizontal extrusions, 16 lofts, revolutions, cylinders, spheres, cones, boxes and 3 platonic shapes), which we may use almost indistinctly to create bottles bodies, cap bases or cap bodies. Some primitive shapes such as cubes, cylinders or cones are also present in the model for simplicity.

As recommended by (Krish, 2011), we use simple shapes, one of each set, as an initial genetic model to explore the solutions space. In order to demonstrate the potential of the model to produce different alternatives, the next figure shows some of the results, grouped by bottle body families.

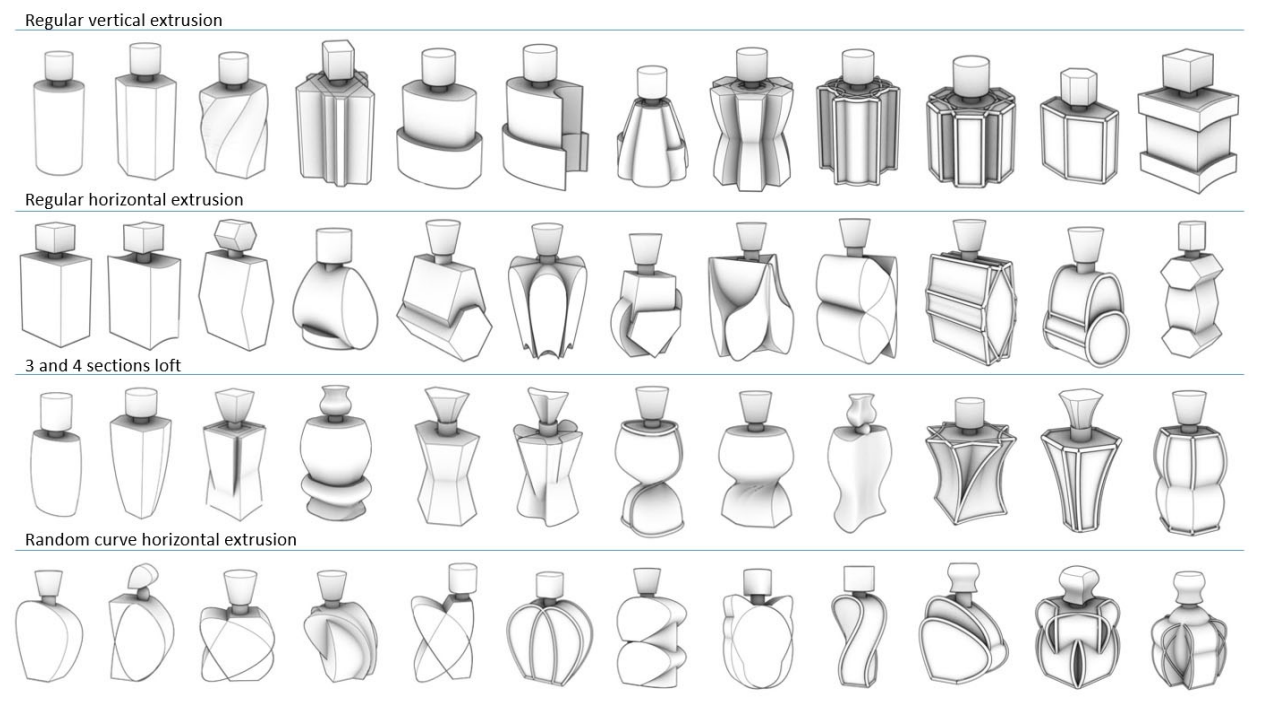

Figure 6. Several body families of perfume bottles

All these variations come from the same genetic model. Unexpected shapes arise relatively easily when the model expresses genes related to basic or secondary transformations. Random curves also generate interesting and organic geometries. Below we show the shape rules applied to build all the solutions of the first group from the initial one. 


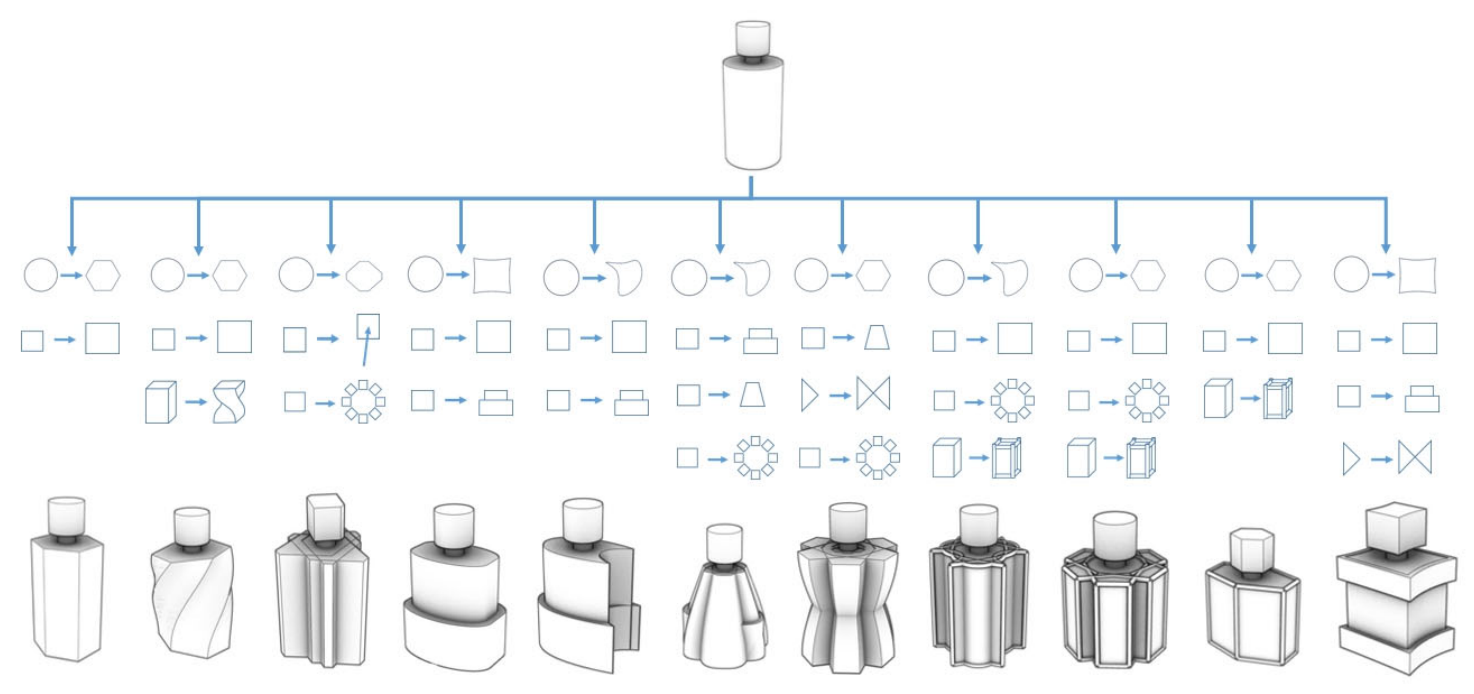

Figure 7. Transformation rules from initial solution

Evidently, these shape rules need the corresponding parameter values to define entirely the resulting solution. Although we have displayed all the rule sequences from the starting basic shape, each solution is reachable from any other. In fact, most of the solutions included derive from intermediate ones through random exploration or manual reformulation. The designer may apply "inverse" shape rules as well, if a random solution turns out more appealing cancelling some features.

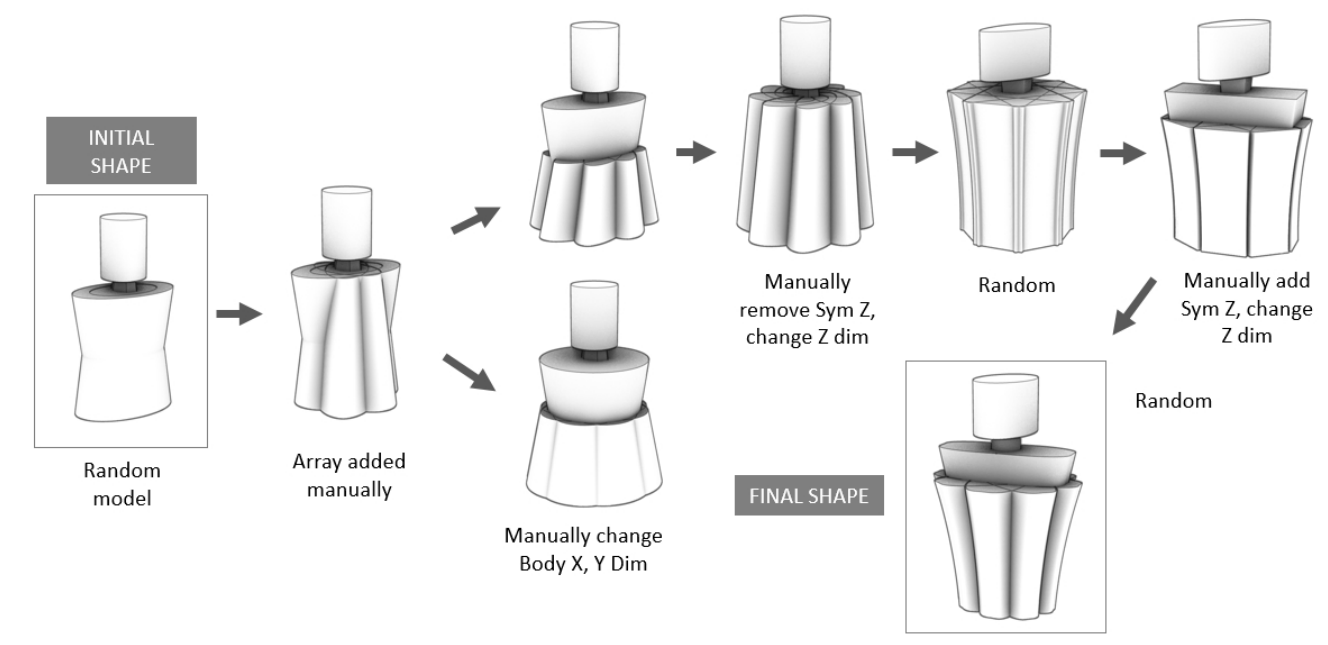

Figure 8. Design flow with reformulation. Manual changes are possible in each step.

An important strategy of designers while sketching solutions is the design families exploration (Lim et al., 2008). The CGM allows this vertical exploration of shapes by playing with the probability of occurrence (PO) of each trait in the solutions. In the following picture, we present different product generations. Those in column A are rendered with $\mathrm{PO}=15 \%$ and $\mathrm{PV}=25 \%$ for all parameters. Groups in column B represent generations with $\mathrm{PV}=25 \%$ but a particular $\mathrm{PO}$ raised to $95 \%$ (for array in the first row, for non-uniform scale in the second). Groups in column $C$ keep these values but increase the probability of a particular shape ("curve revolutions" and "vertical extrusions from symmetric 6-point curves"). Allowing at least a minimum probability for all transformations enhances variability and favours unexpected solutions. In this case, the two solutions highlighted in column B present the same traits (array and non-uniform scale) despite coming from different configurations. 

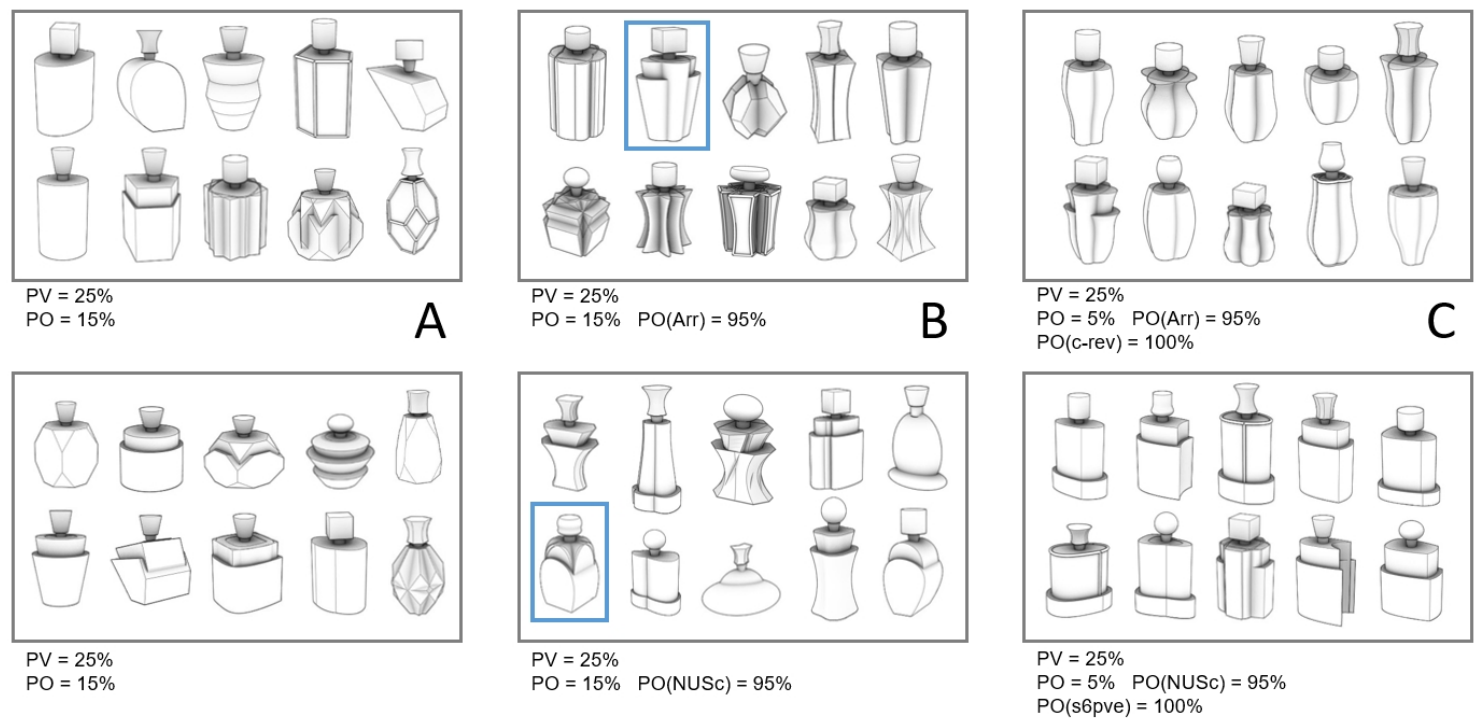

Figure 9. Exploring shape families through probability of occurrence.

This mechanism emulates the "probability density function" used in (Dang et al., 2015). Assigning higher probabilities to desired traits, the designer may control the style of the product while keeping other parameters variable.

TEXT FOR ONLINE VERSION: The whole exploration of the perfume bottle space turned out too large to be fully described here. We have attached a video showing parts of the sessions.

\section{VIDEO01}

\subsection{Table lamps.}

As generality is an important goal of the proposed model, a new case study is prepared to check the transformation of a product structure into a similar one. We use the same product structure of the perfume bottles to generate table lamps, following the work of $(\mathrm{H}$. Liu et al., 2004). The approach of this research is very similar to ours, as the focus lays exclusively on product aesthetic performance, and the designer interactively guides the evolution of the system.

(H. Liu et al., 2004) use a four parts structure (base, body, light and shade). We divide the table lamp into three main volumes (base, body and shade). Therefore, we only need to adjust the boxes proportions in the CGM to obtain a "lamp generator" from the "bottle generator". The product vocabulary area is only modified to add sweep shapes and hollow extrusions, in order to include some features that are relevant to the lamp morphology. The rest of the genetic model remains the same.
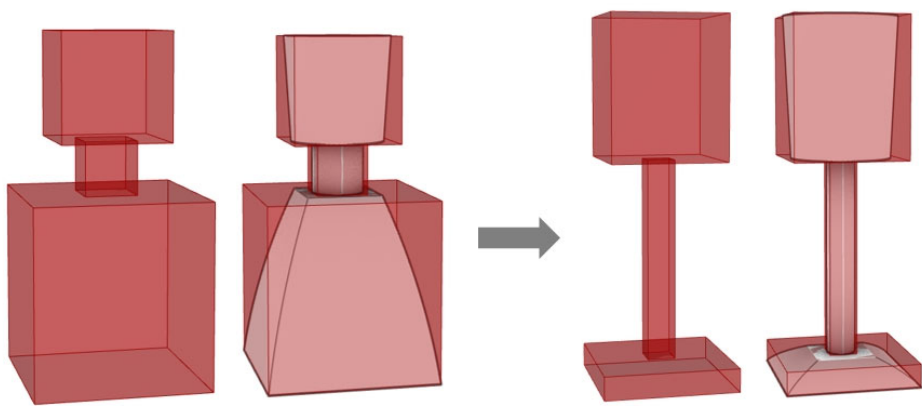
Figure 10. Adapting the perfume bottle structure to the lamp example.

In the following graphic, we present some result grouped by base or by body shape families.

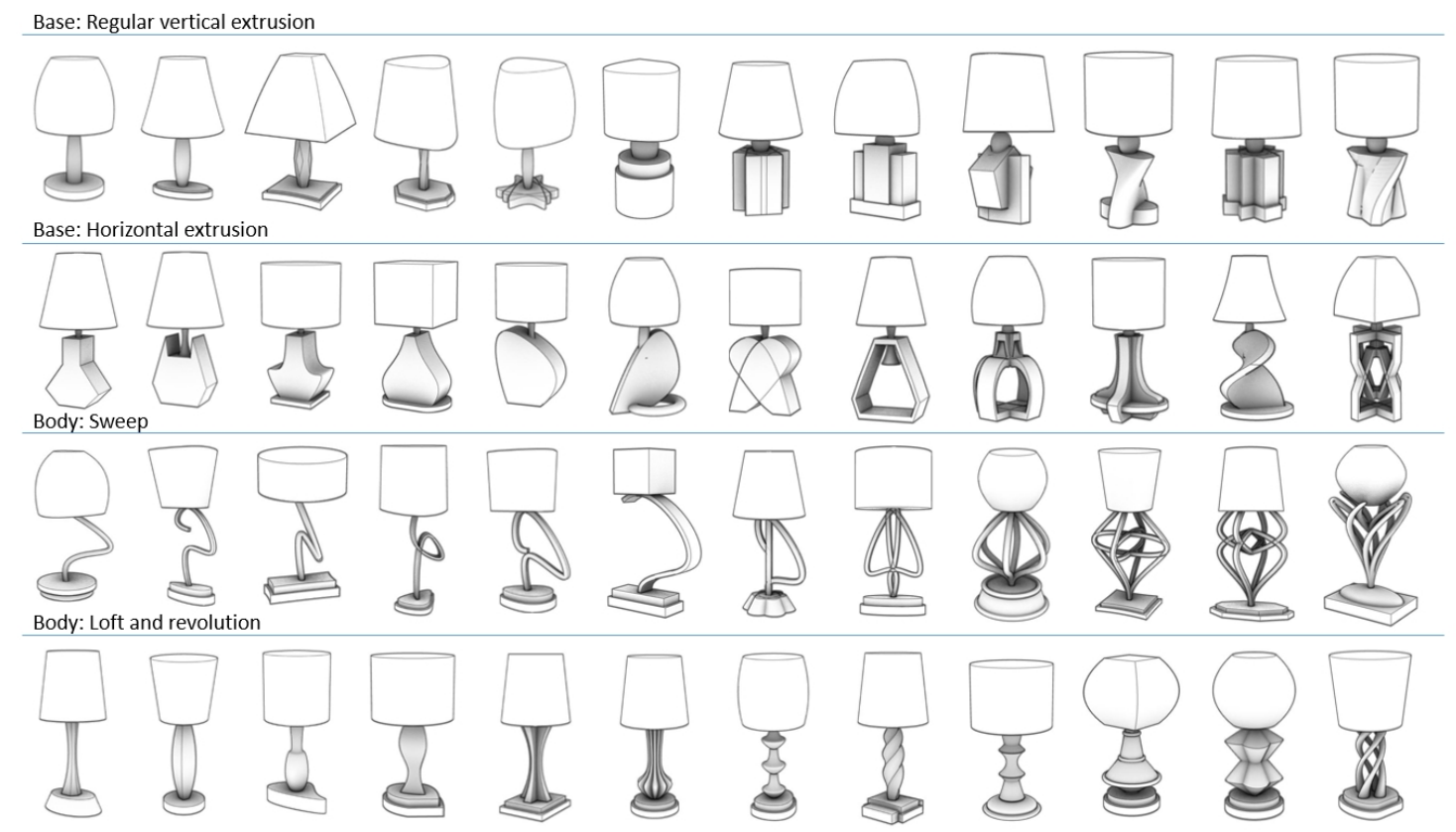

Figure 11. Several lamp families by base and body

A very interesting feature of the proposed CGM is the possibility of transferring traits between products. Once added the sweep and hollow extrusion operations to the lamp model, we thought of inserting them in the previous bottle model (increasing the initial bottle grammar). Two new whole families of concepts emerged in this test, enlarging the design space. This CGM feature represents a good example of the "analogy building" creative strategy (Bernal et al., 2015). It also allows generating stylistically coherent products (bottles and lamps in this case) by using common traits ( $\mathrm{K}$. Chen \& Owen, 1998).
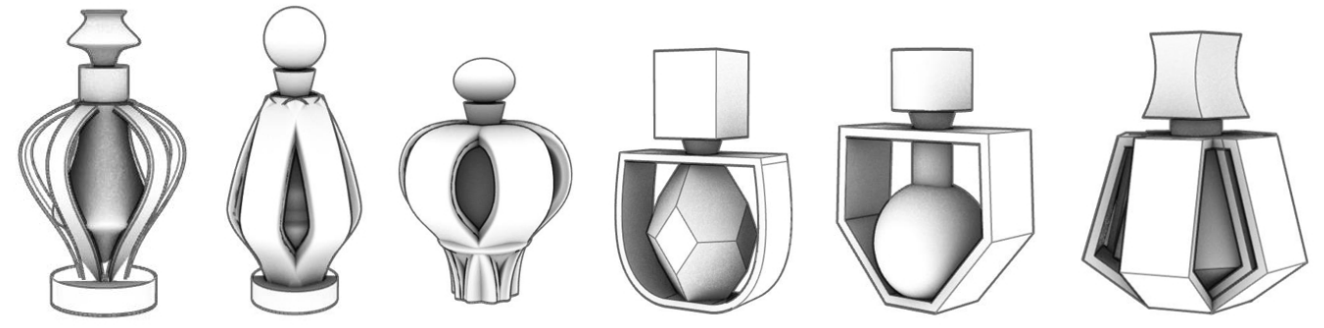

Figure 12. New perfume bottles families through analogy building.

TEXT FOR ONLINE VERSION: As in the previous example, we have attached a video showing part of the exploration session.

\section{VIDEO02}

\subsection{More complex examples.}

Both previous case studies had a very close product structure and little geometric restrictions. A final test was performed using other examples from the literature review: Jewellery rings (Kielarova et al., 2013), coffee makers (Agarwal \& Cagan, 1996; Hsiao 
et al., 2010), office chairs (Hsiao \& Chen, 1997), wheel rims (Gunpinar \& Gunpinar, 2018; Hoisl \& Shea, 2011; Khan \& Gunpinar, 2018; Lim et al., 2008) and, related to this one, motorbikes (Khan \& Awan, 2018; Pugliese \& Cagan, 2002). The goal was to check the model ability to adapt to very different products with varied and more complex geometric requirements.

After analysing the grammar of each product, we adapted the CGM to each structure and vocabulary. Several sets of 20 alternatives were produced, using random generation at start and tweaking some of the concepts.

TEXT FOR ONLINE VERSION: Some raw results and other explorations can be found in the videos attached.

VIDEO03

VIDEO04

VIDEO05

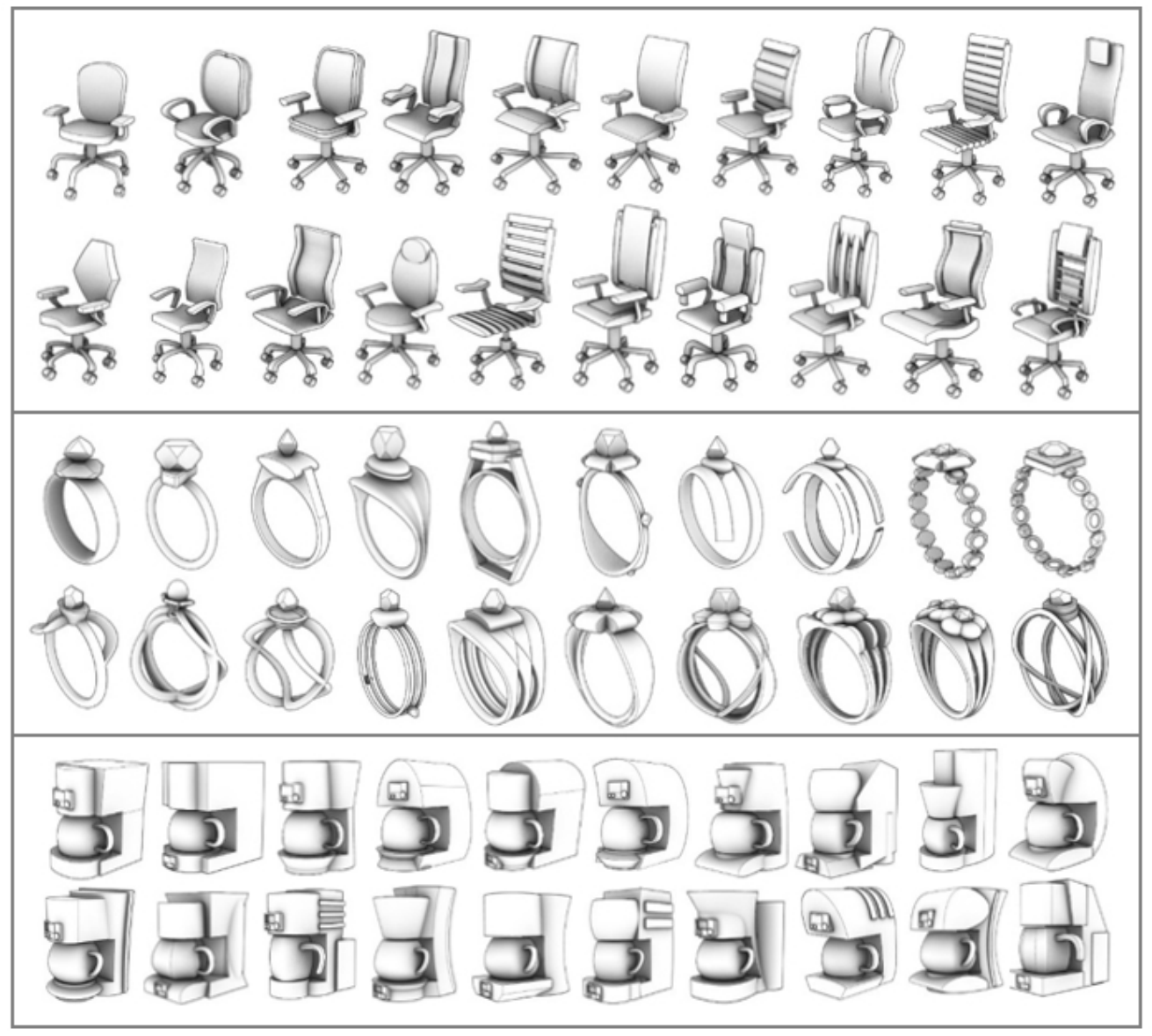

Figure 13. Groups of solutions for office chairs, jewellery rings and coffee makers. 


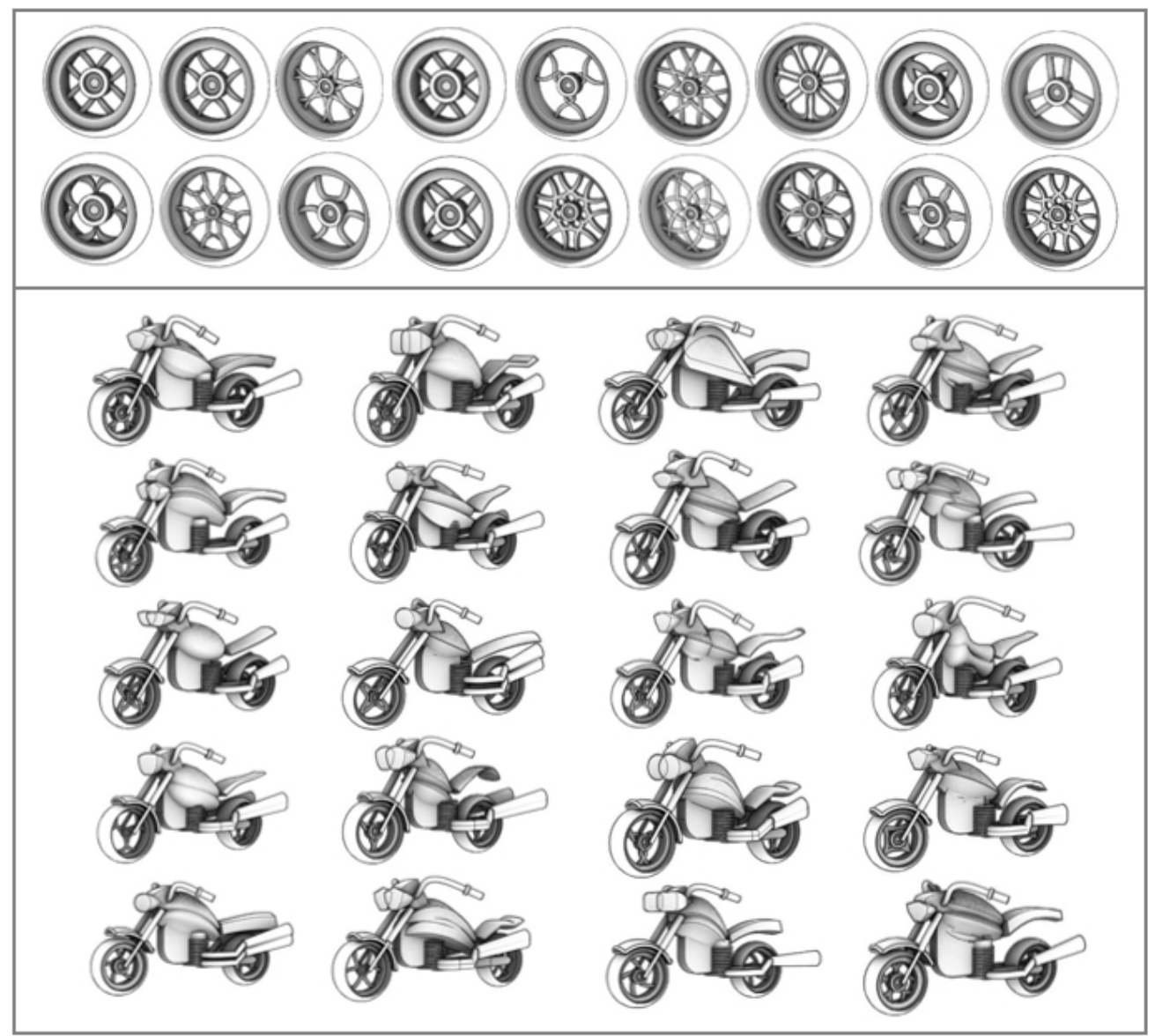

Figure 14. Groups of solutions for rims and motorbikes.

The following table describes the adaptation of the CGM to these products, as well as average and maximum generation times (AGT and MGT). Obtaining the ring model was almost straightforward, as the elements used in the bottle grammar were able to produce most of the shapes identified in the ring study, except the ring itself. The coffee maker model was also relatively easy to achieve. The models for the office chair and the motorbike required a higher degree of adaptation, mainly due to their structures. We used line-based models in order to achieve an easy reorientation of the morph boxes, which were mostly not vertical. This kind of structure base has proved more flexible to complex product configurations and will be generalised in future versions.

\begin{tabular}{|c|c|c|c|c|c|c|c|}
\hline PRODUCT & Perfume bottle & Table lamp & Jewellery ring & Coffee maker & Office chair & Motorcycle wheel rim & Motorcycle \\
\hline STRUCTURE & & & & & & & \\
\hline \#PARAMETERS & 136 & 151 & 171 & 194 & 229 & 28 & 168 \\
\hline AGT (s) & 0.416 & 0.473 & 1.121 & 0.529 & 0.815 & 0.127 & 2.206 \\
\hline MGT (s) & 0.971 & 0.832 & 6.867 & 1.284 & 1.554 & 0.197 & 5.147 \\
\hline $\begin{array}{l}\text { GRAMMAR } \\
\text { MODIFICATIONS }\end{array}$ & BASE CGM & $\begin{array}{l}\text { Sweep curve } \\
\text { Hollow extrusion }\end{array}$ & Ring grammar & $\begin{array}{l}\text { Structure changes } \\
\text { Handle grammar } \\
\text { Custom housing cut } \\
\text { Half point profile } \\
\text { Bend, skew, intersect }\end{array}$ & $\begin{array}{c}\text { Structure changes } \\
\text { S curve } \\
\text { Curve array }\end{array}$ & Structure changes & Structure changes \\
\hline
\end{tabular}


The CGM run on an AMD Ryzen 51400 QuadCore $3.2 \mathrm{GHz}$. The average time needed to produce a new random solution was $0.812 \mathrm{~s}$.

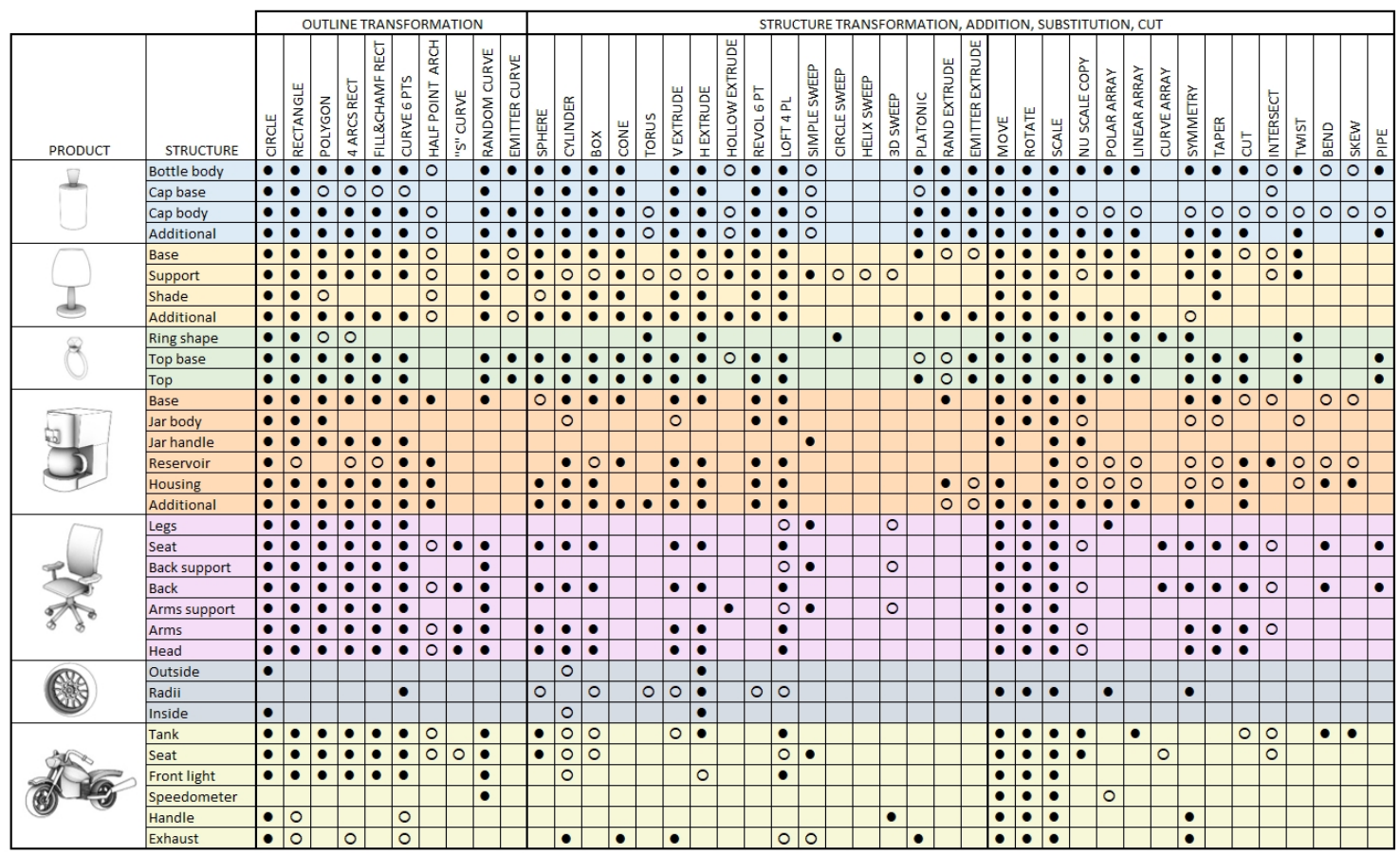

Table 4. Grammar usage by product part

This table summarizes the use of grammar elements in each product during tests. Black dots represent elements (columns) initially included in the product grammar and utilized with coherent results in the corresponding structure part (rows). A result is considered coherent if its geometry respects the basic functionality of the product. White dots represent enlarged grammar, elements that initially where not included or used in that part, but by analogy mechanism, they have been eventually utilized. We have used this information to build a genetic correlation matrix. Although this is a very primary approach, it allows illustrating the CGM potential to adapt to different products. We assign a value of 1 to black dots and 0.5 to white ones. The each cell $(\mathrm{g})$ of the genetic correlation matrix is built from cells of the grammar usage table (a) following this expression:

$$
g_{i j}=\frac{\sum_{k=0}^{n} a_{i k} \times a_{j k}}{\sum_{k=0}^{n} a_{i k} \times a_{i k}}
$$

The matrix reflects common grammar elements between structure parts of the products. The score in cell $A B$ indicates how much of the grammar of $B$ is present in A. Products or parts of products whose rows present many high scores ( $>0.7$, highlighted) utilize a great percentage of the whole general grammar, while those with low scores use only part of it and show less shape variations. Values over 1 represent potential use of grammar elements of B in A. From the matrix, we can observe that:

- Products whose shape is less functionally restricted make more use of the grammar possibilities and in more of their parts when producing suitable solutions.

- Even those products very limited by their geometric functionality present parts with high variation capability. It is possible to adjust and reuse grammars from less restricted products in these parts.

- Parts with similar functional restrictions make use of similar grammar elements. 


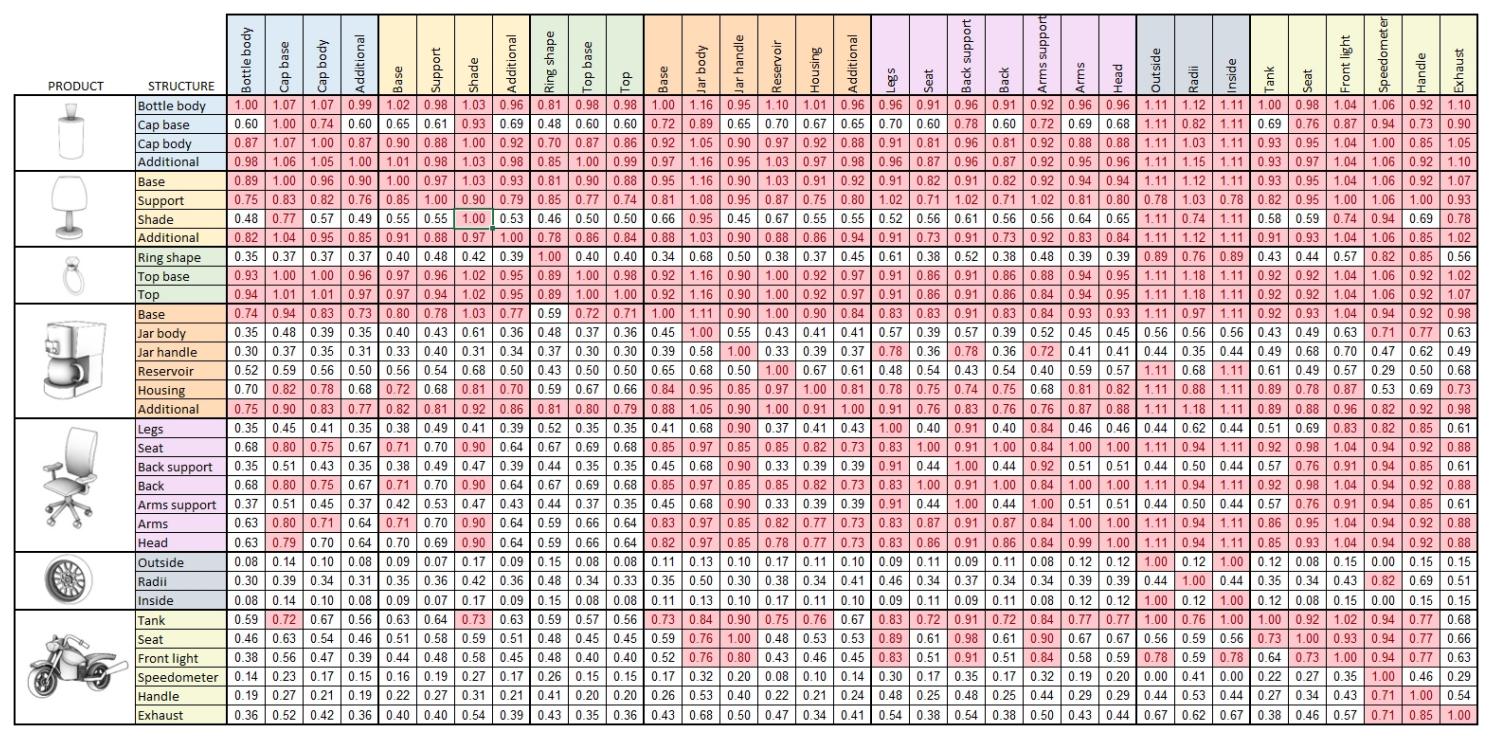

Table 5. Genetic correlation matrix

In the cases studied, perfume bottles, table lamps and rings have made a more intensive use of the grammar elements. The set motorbike-wheel rims, due to its functional configuration, is the most restricted product.

\section{Discussion.}

The CGM performed satisfactorily in all the products tested. Once ready the model, the generation of variations proved very fruitful, even in the most complex cases, and time needed to produce a solution was below one second in average.

The generality of the CGM has been demonstrated by the application to the exploration of design spaces of very different products. Despite this, we think that in this aspect there is room for improvement. An easier manipulation of product structures is desirable to simplify the adaptation to different products. On the other side, changes in the vocabulary needed to switch from a product to another have been reasonably low. However, models of products with higher geometric functionality require more specific grammar items to render productive.

The addition of new items to the grammar increases noticeably the design space, which benefits exploration. In our opinion, the modular flexibility of the CGM constitutes one of its main advantages and makes it outperform previous methods in this aspect. It provides generality, makes the CGM scalable, allows the trait transference feature and even makes possible the use of predefined CAD (or previous CGM) geometry inside a product model.

The CGM mimics the communication cycle between designer and computer described by (Prats et al., 2009). Apart from stimulating emergence through random generation, we have shown that it provide designers with other different creative strategies described in the literature such as reformulation, design families exploration, design by analogy, combination or transformation. We consider that the performance of these features in design practice deserve a particular study and will be subject of future works.

Despite the good results, we are aware that this is an exploratory study and the approach needs more development. The construction of the first model (bottles) was hard and its fine-tuning very demanding, and many aspects of the CGM could be improved and optimized. The use of a particular software is also a limitation. The designer must have a deep understanding of it to achieve a high degree of experimentation, as many shape 
combinations emerge by playing with the model at its lower level. It is possible to prepare interfaces for Grasshopper definitions; however, in our experience they still impose severe limitations to the model interactivity.

Finally, although the tests presented permit an internal validation of the proposal, an external validation would confirm to which extent the method is useful. These complementary studies are part of the future works.

\section{Conclusions.}

In this work, we have presented and tested a generative design technique focused on obtaining a high number of valid aesthetic proposals for product design. The goal was to build a general geometric definition able to produce many different and coherent conceptual shapes of very different products, with minimum changes.

Despite the aforementioned limitations, the results are satisfactory and open an interesting space of research in the adaptation of design creativity theories to generative computer techniques. Advances in modelling and in hardware capabilities are blurring the limits with the detail design stage, making possible to perform calculations over very preliminary conceptual shapes. With many limitations, this would also be possible in our proposal. However, we claim that in the first stages of design a place has to remain free for aesthetic shape exploration.

In this sense, we are working on the enhancement and encoding of the CGM elements, the generation of adaptable product structures and the exploration of workflow possibilities. It is possible to connect several instances of the CGM to explore parts separately. Designers may create and reutilize repositories of CGM generated geometry to increase performance. The consideration of particular cases is also under study. For instance, products characterized by just one main volume with significant surface variations (shoes, helmets, electronic devices) or very organic shapes need a specific approach. A connection with some machine learning mechanism to help designers to evaluate concepts is also under development.

As a final reflection, we consider that a complete implementation of computer aided conceptual design requires a change in the way we design today. In (Lin \& Lee, 2013), the authors differentiate between generative designers (people who design the generative system) and industrial designers (people who use the generative system to design products). Maybe this distinction makes sense nowadays, but in our opinion, it will be fading with time. The design of a generative system determines completely the solutions space that it is able to explore. In fact, it requires creativity to design a prolific generative system and to experiment with it. It is not a closed tool used to produce variations by switching controls. It is open and evolves with the solution. Just as sketches do.

This research did not receive any specific grant from funding agencies in the public, commercial, or not-for-profit sectors.

\section{References}

Agarwal, M., \& Cagan, J. (1996). A Blend of Different Tastes: The Language of Coffeemakers. Environment and Planning B: Planning and Design, 25(2), 205-226. https://doi.org/10.1068/b250205 
Alcaide-Marzal, J., Diego-Más, J. A., Asensio-Cuesta, S., \& Piqueras-Fiszman, B. (2013). An exploratory study on the use of digital sculpting in conceptual product design. Design Studies, 34(2), 264-284.

https://doi.org/10.1016/J.DESTUD.2012.09.001

Aqeel, A. Bin. (2015). Development of Visual Aspect of Porsche Brand using CAD Technology. Procedia Technology, 20, 170-177. https://doi.org/10.1016/J.PROTCY.2015.07.028

Bae, S.-H., Balakrishnan, R., \& Singh, K. (2008). ILoveSketch: as-natural-aspossible sketching system for creating 3D curve models. In S. B. Cousins \& M. Beaudouin-Lafon (Eds.), Proceedings of the 21st annual ACM symposium on User interface software and technology (pp. 151-160). ACM. https://doi.org/10.1145/1449715.1449740

Bentley, P. J. (1998). Aspects of Evolutionary Design by Computers. In Advances in Soft Computing Engineering Design and Manufacturing SpringerVerlag, 44(0).

Bernal, M., Haymaker, J. R., \& Eastman, C. (2015). On the role of computational support for designers in action. Design Studies, 41, 163182. https://doi.org/10.1016/J.DESTUD.2015.08.001

Boden, M. A. (2004). The creative mind: myths and mechanisms (2nd editio). Routledge.

Chang, Y.-S., Chien, Y.-H., Lin, H.-C., Yiching, M. C., \& Hsieh, H.-H. (2016). Effects of 3D CAD applications on the design creativity of students with different representational abilities. Computers in Human Behavior, 65, 107113. https://doi.org/10.1016/J.CHB.2016.08.024

Chase, S. C. (2002). A model for user interaction in grammar-based design systems. Automation in Construction, 11(2), 161-172.

https://doi.org/10.1016/S0926-5805(00)00101-1

Chase, S. C. (2005). Generative design tools for novice designers: Issues for selection. Automation in Construction, 14(6), 689-698.

Chen, K., \& Owen, C. L. (1998). A study of computer-supported formal design. Design Studies, 19(3), 331-359. https://doi.org/10.1016/S0142694X(98)00002-7

Chen, X., \& McKay, A. (2004). Package shape design principles to support brand identity. 14th IAPRI World ..., 1-14.

Cleveland, P. (2010). Style based automated graphic layouts. Design Studies, 31(1), 3-25. https://doi.org/10.1016/J.DESTUD.2009.06.003

Cluzel, F., Yannou, B., \& Dihlmann, M. (2012). Using evolutionary design to interactively sketch car silhouettes and stimulate designer's creativity. Engineering Applications of Artificial Intelligence, 25(7), 1413-1424. https://doi.org/10.1016/j.engappai.2012.02.011

Company, P., Contero, M., Varley, P., Aleixos, N., \& Naya, F. (2009). 
Computer-aided sketching as a tool to promote innovation in the new product development process. Computers in Industry, 60(8), 592-603.

Cook, M. T., \& Agah, A. (2009). A survey of sketch-based 3-D modeling techniques. Interacting with Computers, 21(3), 201-211. https://doi.org/10.1016/j.intcom.2009.05.004

Crilly, N. (2015). Fixation and creativity in concept development: The attitudes and practices of expert designers. Design Studies, 38, 54-91. https://doi.org/10.1016/J.DESTUD.2015.01.002

Crilly, N., \& Cardoso, C. (2017). Where next for research on fixation, inspiration and creativity in design? Design Studies, 50, 1-38. https://doi.org/10.1016/J.DESTUD.2017.02.001

Cross, N. (1997). Descriptive models of creative design: application to an example. Design Studies, 18(4), 427-440. https://doi.org/10.1016/S0142694X(97)00010-0

Cross, N. (2008). Engineering Design Methods: Strategies for Product Design. Design (Vol. 58). Wiley.

Dang, M., Lienhard, S., Ceylan, D., Neubert, B., Wonka, P., \& Pauly, M. (2015). Interactive design of probability density functions for shape grammars. ACM Transactions on Graphics, 34(6), 1-13. https://doi.org/10.1145/2816795.2818069

Dekker, K. (1992). A future interface for computer-aided styling. Design Studies, 13(1), 42-53. https://doi.org/10.1016/0142-694X(92)80004-I

Do, E. Y.-L., Gross, M. D., Neiman, B., \& Zimring, C. (2000). Intentions in and relations among design drawings. Design Studies, 21(5), 483-503.

Dorst, K., \& Cross, N. (2001). Creativity in the design process: co-evolution of problem-solution. Design Studies, 22(5), 425-437. https://doi.org/10.1016/S0142-694X(01)00009-6

Dou, R., Zong, C., \& Nan, G. (2016). Multi-stage interactive genetic algorithm for collaborative product customization. Knowledge-Based Systems, 92, 43-54. https://doi.org/10.1016/J.KNOSYS.2015.10.013

Gabriel, A., Monticolo, D., Camargo, M., \& Bourgault, M. (2016). Creativity support systems: A systematic mapping study. Thinking Skills and Creativity, 21, 109-122. https://doi.org/10.1016/J.TSC.2016.05.009

Gero, J. S. (1996). Creativity, emergence and evolution in design. KnowledgeBased Systems, 9(7), 435-448. https://doi.org/10.1016/S09507051(96)01054-4

Gero, J. S. (2000). Computational Models of Innovative and Creative Design Processes. Technological Forecasting and Social Change, 64(2), 183-196. https://doi.org/10.1016/S0040-1625(99)00105-5

Goel, V. (1995). Sketches of Thought. MIT Press. 
Goldschmidt, G. (1991). The dialectics of sketching. Creativity Research Journal, 4(2), 123-143.

Gong, D.-W., Hao, G.-S., Zhou, Y., \& Sun, X.-Y. (2007). Interactive genetic algorithms with multi-population adaptive hierarchy and their application in fashion design. Applied Mathematics and Computation, 185(2), 10981108. https://doi.org/10.1016/j.amc.2006.07.043

Granadeiro, V., Duarte, J. P., Correia, J. R., \& Leal, V. M. S. (2013). Building envelope shape design in early stages of the design process: Integrating architectural design systems and energy simulation. Automation in Construction, 32, 196-209. https://doi.org/10.1016/j.autcon.2012.12.003

Gu, Z., Xi Tang, M., \& Frazer, J. H. (2006). Capturing aesthetic intention during interactive evolution. Computer-Aided Design, 38(3), 224-237. https://doi.org/10.1016/J.CAD.2005.10.008

Gunpinar, E., \& Gunpinar, S. (2018). A shape sampling technique via particle tracing for CAD models. Graphical Models, 96, 11-29. https://doi.org/10.1016/J.GMOD.2018.01.003

Hewett, T. T. (2005). Informing the design of computer-based environments to support creativity. International Journal of Human-Computer Studies, 63(4), 383-409. https://doi.org/10.1016/j.ijhcs.2005.04.004

Hoisl, F., \& Shea, K. (2011). An interactive, visual approach to developing and applying parametric 3D spatial grammars. Al EDAM, 25, 333-356. https://doi.org/10.1017/S0890060411000205

Hsiao, S.-W., \& Chen, C.-H. (1997). A semantic and shape grammar based approach for product design. Design Studies, 18(3), 275-296. https://doi.org/10.1016/S0142-694X(97)00037-9

Hsiao, S.-W., Chiu, F.-Y., \& Lu, S.-H. (2010). Product-form design model based on genetic algorithms. International Journal of Industrial Ergonomics, 40(3), 237-246. https://doi.org/10.1016/J.ERGON.2010.01.009

Hsiao, S.-W., \& Tsai, H.-C. (2005). Applying a hybrid approach based on fuzzy neural network and genetic algorithm to product form design. International Journal of Industrial Ergonomics, 35(5), 411-428.

https://doi.org/10.1016/j.ergon.2004.10.007

Hsiao, S.-W., \& Wang, H.-P. (1998). Applying the semantic transformation method to product form design. Design Studies, 19(3), 309-330. https://doi.org/10.1016/S0142-694X(98)00009-X

Hu, Z.-H., Ding, Y.-S., Zhang, W.-B., \& Yan, Q. (2008). An interactive coevolutionary CAD system for garment pattern design. Computer-Aided Design, 40(12), 1094-1104. https://doi.org/10.1016/J.CAD.2008.10.010

Hybs, I., \& Gero, J. S. (1992). An evolutionary process model of design. Design Studies, 13(3), 273-290. https://doi.org/10.1016/0142-694X(92)90216-W

Hyun, K. H., \& Lee, J.-H. (2018). Balancing homogeneity and heterogeneity in 
design exploration by synthesizing novel design alternatives based on genetic algorithm and strategic styling decision. Advanced Engineering Informatics, 38, 113-128. https://doi.org/10.1016/J.AEI.2018.06.005

Igarashi, T., Matsuoka, S., \& Tanaka, H. (1999). Teddy: a sketching interface for 3D freeform design. Proceedings of the 26th Annual Conference on Computer Graphics and Interactive Techniques - SIGGRAPH '99, 409416. https://doi.org/10.1145/311535.311602

Jansson, D. G., \& Smith, S. M. (1991). Design fixation. Design Studies, 12(1), 3-11. https://doi.org/10.1016/0142-694X(91)90003-F

Kelly, J., Papalambros, P. Y., \& Seifert, C. M. (2008). Interactive Genetic Algorithms for Use as Creativity Enhancement Tools. In AAAI Spring Symposium: Creative Intelligent Systems.

Khan, S., \& Awan, M. J. (2018). A generative design technique for exploring shape variations. Advanced Engineering Informatics, 38, 712-724. https://doi.org/10.1016/J.AEl.2018.10.005

Khan, S., \& Gunpinar, E. (2018). Sampling CAD models via an extended teaching-learning-based optimization technique. Computer-Aided Design, 100, 52-67. https://doi.org/10.1016/j.cad.2018.03.003

Kicinger, R., Arciszewski, T., \& Jong, K. De. (2005). Evolutionary computation and structural design: A survey of the state-of-the-art. Computers \& Structures, 83(23), 1943-1978. https://doi.org/10.1016/j.compstruc.2005.03.002

Kielarova, S. W., Pradujphongphet, P., \& Bohez, E. L. J. (2015). New Interactive-Generative Design System: Hybrid of Shape Grammar and Evolutionary Design - An Application of Jewelry Design. In Advances in Swarm and Computational Intelligence (pp. 302-313). Springer. https://doi.org/10.1007/978-3-319-20466-6_33

Kielarova, S. W., Pradujphongphet, P., \& Bohez, I. L. J. (2013). An approach of generative design system: Jewelry design application. In IEEE International Conference on Industrial Engineering and Engineering Management (pp. 1329-1333). https://doi.org/10.1109/IEEM.2013.6962626

Kielarova, S. W., \& Sansri, S. (2017). Shape Optimization in Product Design Using Interactive Genetic Algorithm Integrated with Multi-objective Optimization. In Multi-disciplinary Trends in Artificial Intelligence (Vol. 10607, pp. 76-86). https://doi.org/10.1007/978-3-319-69456-6

Kim, H.-S., \& Cho, S.-B. (2000). Application of interactive genetic algorithm to fashion design. Engineering Applications of Artificial Intelligence, 13(6), 635-644. https://doi.org/10.1016/S0952-1976(00)00045-2

Krish, S. (2011). A practical generative design method. CAD Computer Aided Design, 43(1), 88-100.

Lee, H. C., Herawan, T., \& Noraziah, A. (2012). Evolutionary grammars based design framework for product innovation. Procedia Technology, 1, 132- 
136. https://doi.org/10.1016/j.protcy.2012.02.026

Lee, H., \& Tang, M. (2006). Generating stylistically consistent product form designs using interactive evolutionary parametric shape grammars. In 2006 7th International Conference on Computer-Aided Industrial Design and Conceptual Design (pp. 1-6). Hangzhou, China: IEEE. https://doi.org/10.1109/CAIDCD.2006.329391

Lim, S., Prats, M., Jowers, I., Chase, S., Garner, S., \& Mckay, A. (2008). Shape Exploration in Design: Formalising and Supporting a Transformational Process. International Journal of Architectural Computing, 6(4), 415-433. https://doi.org/10.1260/147807708787523303

Lin, M.-H., \& Lee, L.-C. (2013). An Experimental Study for Applying Generative Design to Electronic Consumer Products. Part IV LNCS, 8015, 392-401. https://doi.org/10.1007/978-3-642-39253-5_43

Liu, H., Tang, M., \& Frazer, J. H. (2004). Supporting creative design in a visual evolutionary computing environment. Advances in Engineering Software, 35(5), 261-271.

Liu, X., Li, Y., Pan, P., \& Li, W. (2011). Research on computer-aided creative design platform based on creativity model. Expert Systems with Applications, 38(8), 9973-9990. https://doi.org/10.1016/J.ESWA.2011.02.032

Lo, C.-H., Ko, Y.-C., \& Hsiao, S.-W. (2015). A study that applies aesthetic theory and genetic algorithms to product form optimization. Advanced Engineering Informatics, 29(3), 662-679. https://doi.org/10.1016/J.AEl.2015.06.004

Lubart, T. (2005). How can computers be partners in the creative process: Classification and commentary on the Special Issue. International Journal of Human-Computer Studies, 63(4-5), 365-369.

https://doi.org/10.1016/j.ijhcs.2005.04.002

Machado, T. L. D. A., Gomes, A. S., \& Walter, M. (2009). A Comparison Study: Sketch-Based Interfaces versus WIMP Interfaces in Three Dimensional Modeling Tasks. 2009 Latin American Web Congress, 29-35. https://doi.org/10.1109/LA-WEB.2009.22

McCormack, J. P., Cagan, J., \& Vogel, C. M. (2004). Speaking the Buick language: capturing, understanding, and exploring brand identity with shape grammars. Design Studies, 25(1), 1-29.

McKay, A., Ang, M. C., Chau, H. H., \& Pennington, A. de. (2006). Combining Evolutionary Algorithms And Shape Grammars To Generate Branded Product Design. In Design Computing and Cognition '06 (pp. 521-539). Dordrecht: Springer Netherlands. https://doi.org/10.1007/978-1-4020-51319_27

Mok, P. Y., Xu, J., Wang, X. X., Fan, J. T., Kwok, Y. L., \& Xin, J. H. (2013). An IGA-based design support system for realistic and practical fashion 
designs. CAD Computer Aided Design, 45(11).

https://doi.org/10.1016/j.cad.2013.06.014

O’Neill, M., MarkSwafford, J., Hemberg, E., McDermott, J., Byrne, J., \& Brabazon, A. (2010). Evolutionary design using grammatical evolution and shape grammars: designing a shelter. International Journal of Design Engineering, 3(1).

Obrenovic, Z. (2009). Sketching and Creativity. Creativity.

Olsen, L., Samavati, F. F., Sousa, M. C., \& Jorge, J. A. (2009). Sketch-based modeling: A survey. Computers and Graphics (Pergamon), 33(1), 85-103. https://doi.org/10.1016/j.cag.2008.09.013

Prats, M., Lim, S., Jowers, I., Garner, S. W., \& Chase, S. (2009). Transforming shape in design: observations from studies of sketching. Design Studies, 30(5), 503-520.

Pugliese, M. J., \& Cagan, J. (2002). Capturing a rebel: modeling the HarleyDavidson brand through a motorcycle shape grammar. Research in Engineering Design. https://doi.org/10.1007/s00163-002-0013-1

Rahimian, F. P., \& Ibrahim, R. (2011). Impacts of VR 3D sketching on novice designers' spatial cognition in collaborative conceptual architectural design. Design Studies, 32(3), 255-291. https://doi.org/10.1016/j.destud.2010.10.003

Renner, G., \& Ekárt, A. (2003). Genetic algorithms in computer aided design. Computer-Aided Design, 35(8), 709-726. https://doi.org/10.1016/S00104485(03)00003-4

Robertson, B. F., \& Radcliffe, D. F. (2009). Impact of CAD tools on creative problem solving in engineering design. Computer-Aided Design, 41(3), 136-146.

Rodrigues, E., Amaral, A. R., Gaspar, A. R., \& Gomes, Á. (2015). An Approach to Urban Quarter Design Using Building Generative Design and Thermal Performance Optimization. Energy Procedia, 78, 2899-2904. https://doi.org/10.1016/j.egypro.2015.11.662

Ruiz-Montiel, M., Boned, J., Gavilanes, J., Jiménez, E., Mandow, L., \& Pérezde-la-Cruz, J.-L. (2013). Design with shape grammars and reinforcement learning. Advanced Engineering Informatics, 27(2), 230-245. https://doi.org/10.1016/j.aei.2012.12.004

Samavati, L. O. F. F., Sousa, M. C., \& Jorge, J. (2008). A Taxonomy of Modeling Techniques using Sketch-Based Interfaces. Techniques, 39-57.

Schon, D. A., \& Wiggins, G. (1992). Kinds of seeing and their functions in designing. Design Studies, 13(2), 135-156.

Selker, T. (2005). Fostering motivation and creativity for computer users. International Journal of Human-Computer Studies, 63(4-5), 410-421. https://doi.org/10.1016/J.IJHCS.2005.04.005 
Shea, K., Aish, R., \& Gourtovaia, M. (2005). Towards integrated performancedriven generative design tools. Automation in Construction, 14(2), 253264. https://doi.org/10.1016/j.autcon.2004.07.002

Shieh, M.-D., Li, Y., \& Yang, C.-C. (2018). Comparison of multi-objective evolutionary algorithms in hybrid Kansei engineering system for product form design. Advanced Engineering Informatics, 36, 31-42. https://doi.org/10.1016/J.AEl.2018.02.002

Singh, V., \& Gu, N. (2011). Towards an integrated generative design framework. Design Studies, In Press, . https://doi.org/10.1016/j.destud.2011.06.001

Stiny, G., \& Gips, J. (1972). Shape grammars and the generative specification of painting and sculpture. Information Processing 71 Proceedings of the IFIP Congress 1971. Volume 2, 71, 1460-1465.

Stones, C., \& Cassidy, T. (2010). Seeing and discovering: how do student designers reinterpret sketches and digital marks during graphic design ideation? Design Studies, 31(5), 439-460.

Su, J., \& Zhang, S. (2010). Research on Product Shape Innovation Design Method with Human-Computer Interaction Through Genetic Algorithm THE CHARACTERISTIC ANALYSIS OF HUMAN AND. Interface, 301-305.

Sun, J., Frazer, J. H., \& Mingxi, T. (2007). Shape optimisation using evolutionary techniques in product design. Computers \& Industrial Engineering, 53(2), 200-205. https://doi.org/10.1016/J.CIE.2007.06.010

Sun, X., Gong, D., \& Zhang, W. (2012). Interactive genetic algorithms with large population and semi-supervised learning. Applied Soft Computing, 12(9), 3004-3013. https://doi.org/10.1016/J.ASOC.2012.04.021

Suwa, M., \& Tversky, B. (1997). What do architects and students perceive in their design sketches? A protocol analysis. Design Studies, 18(4), 385403.

Tovey, M. (1997). Styling and design: intuition and analysis in industrial design. Design Studies, 18(1), 5-31. https://doi.org/10.1016/S0142694X(96)00006-3

Troiano, L., \& Birtolo, C. (2014). Genetic algorithms supporting generative design of user interfaces: Examples. Information Sciences, 259, 433-451. https://doi.org/10.1016/j.ins.2012.01.006

Turrin, M., von Buelow, P., \& Stouffs, R. (2011). Design explorations of performance driven geometry in architectural design using parametric modeling and genetic algorithms. Advanced Engineering Informatics, 25(4), 656-675. https://doi.org/10.1016/j.aei.2011.07.009

van Dijk, C. G. C. (1995). New insights in computer-aided conceptual design. Design Studies, 16(1), 62-80. https://doi.org/10.1016/0142694X(95)90647-X 
van Dijk, C. G. C., \& Mayer, A. A. C. (1997). Sketch input for conceptual surface design. Computers in Industry, 34(1), 125-137.

Van Elsas, P., \& Vergeest, J. (1998). New functionality for computer-aided conceptual design: the displacement feature. Design Studies, 19(1), 81102. https://doi.org/10.1016/S0142-694X(97)00016-1

van Sommers, P. (1984). Drawing and cognition: Descriptive and experimental studies of graphic production processes. Cambridge University Press .

Vasconcelos, L. A., \& Crilly, N. (2016). Inspiration and fixation: Questions, methods, findings, and challenges. Design Studies, 42, 1-32. https://doi.org/10.1016/J.DESTUD.2015.11.001

Vuletic, T., Duffy, A., Hay, L., McTeague, C., Pidgeon, L., \& Grealy, M. (2018). The challenges in computer supported conceptual engineering design. Computers in Industry, 95, 22-37. https://doi.org/10.1016/J.COMPIND.2017.11.003

Wang, K., \& Nickerson, J. V. (2017). A literature review on individual creativity support systems. Computers in Human Behavior, 74, 139-151. https://doi.org/10.1016/J.CHB.2017.04.035 